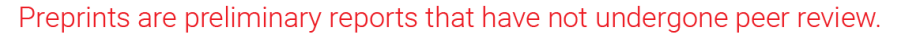 \\ They should not be considered conclusive, used to inform clinical practice, \\ or referenced by the media as validated information. \\ Evolution of Vortex At The Runner Area of Pump- Turbine Under The Runaway Condition
}

Qifei Li ( $\nabla$ lqfy@lut.edu.cn )

Lanzhou University of Technology

\section{Feng Zhou}

Lanzhou University of Technology

Chaoben Zhao

Lanzhou University of Technology

Qi Huang

Lanzhou University of Technology

Zhenggui Li

Xihua University

\section{Research}

Keywords: pump-turbine, runaway condition, coherent structure, channel vortices, numerical simulation

Posted Date: February 19th, 2021

DOI: https://doi.org/10.21203/rs.3.rs-213235/v1

License: (c) (i) This work is licensed under a Creative Commons Attribution 4.0 International License.

Read Full License 


\title{
Evolution of vortex at the runner area of pump-turbine under the runaway condition
}

\author{
Qifei Li ${ }^{1,2, *}$, Feng Zhou ${ }^{1}$, Chaoben Zhao ${ }^{1}$, Qi Huang ${ }^{1}$ and Zhenggui Li $^{3}$
}

${ }^{1}$ College of Energy and Power Engineering, Lanzhou University of Technology, Lanzhou 730050, P. R. China

${ }^{2}$ State Key Laboratory of Gansu Fluid Machinery and Systems, Lanzhou University of Technology, Lanzhou 730050, P. R. China

${ }^{3}$ Key Laboratory of Fluid and Power Machinery of the Ministry of Education, Xihua University, Chengdu 610039, P. R. China

*Correspondence: lqfy@lut.edu.cn; 2546554908@qq.com

\begin{abstract}
To study the evolution principle of the coherent structure in the low flow rate runaway condition, the pump-turbine of the certain pumped storage power plant is employed. The transient dynamic stress of the runner has been numerically simulated and examined in this study, in order that can probe the mechanism of channel vortices acting on the blade and the evolution of their coherent structure in the runner. Based on the Realizable $k-\varepsilon$ turbulent model, the unsteady flow of the whole pump-turbine channels is calculated. Results show that the flow in the runner channels presents with the turbulence state, and with many different scales vortices. These vortices structures are mainly distributed in the inlet region of the blade, the area of the blade trailing edge and the middle section of the runner channels. These vortex structures affect the distribution of the blade pressure load. Moreover, vortices structure at the inlet of the runner depends on the change of the attack angle. In the flow region formed at the outlet of the blade near the suction surface and the runner cone, the blade has a limited effect to the fluid, thus the vortex structure depends on the Coriolis force and the centrifugal force joint action.
\end{abstract}

Keywords: pump-turbine, runaway condition, coherent structure, channel vortices, numerical simulation

\section{Introduction}

Quite a large number of high dams and large reservoirs were built in China, notably including the high-head pumped storage, seeing that their unique and irreplaceable roles in the peak regulation of power network, the energy structure regulated, the irrigation, and the tourism [1-5]. In the production practice of the power station, the pump-turbines are subjected to rapid switching between the pumping and generating modes with extended operation under off-design conditions. Thus the electricity network frequency will be maintained stable, and the standard and orderly distribution of electric power will be ensured [6]. In particular, during the start-up procedure, the generator unit is in the runaway operation. This process is a crucial reference to evaluate the operation stability of the power station. The runaway condition, as the representative of the unstable operation of the pump-turbine, may lead to a series of destabilization caused by inertial inertia force. Moreover, it is well known that such an unstable operation will lead to a significant increase in secondary flow, backflow, and motivate the large scale and high-intensity vortex motion [7]. Those flow statues are inevitably accompanied by the serious of vibrations and noise. Therefore, the evolution of channel vortex is of considerable significance to the stable operation. Shi et al. [8] performed numerical calculation and model experiments on the turbine of Gong zui power station and proposed the concept of gas supply to weaken the channel vortex. Zhang et al. [9] proposed the one caused of channel vortex is pressure fluctuation. Li et al. [10] conducted the 3-D CFD simulations of water flow during hydraulic transients in the runner of a hydropower 
station and measured the frequency characteristics of channel vortex. LMH-EPFL lab experimentally showed flow patterns inside a model unit at the turbine-brake condition[11,12]. Also, numerical studies which may indicate the stability well[13-15]. The CFD simulations on the flow pattern inside pump-turbine were also impressive[16-17].

Those studies have been introduced in terms of the causes of channel vortex, however, there are few studies on the evolutionary and interactions of the leaf channel vortex.

\begin{tabular}{|cc|}
\hline Nomenclature & \\
$H$ & head $(\mathrm{m})$ \\
$H_{\mathrm{m}}$ & Test hydraulic head $(\mathrm{m})$ \\
$n$ & rotational speed \\
$q_{\mathrm{m}}$ & discharge of the pump $\left(\mathrm{kg}^{-1}\right)$ \\
$y+$ & dimensionless wall distance \\
$n_{11}$ & unit rota peed $(\mathrm{r} / \mathrm{min})$ \\
$Q_{11}$ & unit discharge $\left(\mathrm{m}^{3} / \mathrm{s}\right)$ \\
$A_{0}$ & guide vane opening $(\mathrm{mm})$ \\
$n_{t 11}$ & unit speed of experimental test $(\mathrm{r} / \mathrm{min})$ \\
$Q_{t 11}$ & unit flow of experimental test $\left(\mathrm{m}^{3} / \mathrm{s}\right)$ \\
$n_{s 11}$ & unit speed of simulation $(\mathrm{r} / \mathrm{min})$ \\
$Q_{s 11}$ & unit flow of simulation $\left(\mathrm{m}^{3} / \mathrm{s}\right)$ \\
\hline
\end{tabular}

The complex flow characteristics in the runner channel, the 3-D simulations of hydraulic transients are necessary. Therefore, this paper simulated the flow in runner channel using the Realizable k-method, ed, mad the leaves relatively stationary and the evolution of channel vortex are clarified, and their characteristics are analyzed by the method of correcting the blade rotation angle under the runaway speed operating conditions.

\section{Method}

\subsection{Geometry model}

The mixed flow pump-turbine model with a single centrifugal rotor is shown in Fig. The geometry parameters of the pump-turbine are listed in Table 1.

Tab. 1The geometry parameters of the pump-turbine

\begin{tabular}{ccc}
\hline Parameter & Symbol & Value \\
\hline Diameter of the high-pressure side of the runner $/ \mathrm{mm}$ & $D_{1}$ & 473.6 \\
Diameter of the low-pressure side of the runner $/ \mathrm{mm}$ & $D_{2}$ & 300 \\
Runner blade number & $Z_{r}$ & 9 \\
Guide vane number & $Z_{g}$ & 20 \\
Stay vane number & $Z_{s}$ & 20 \\
Outlet diameter of draft tube $/ \mathrm{mm}$ & $D_{l m}$ & 660 \\
Inlet diameter of volute $/ \mathrm{mm}$ & $D_{2 m}$ & 315 \\
Guide vane height $/ \mathrm{mm}$ & $b_{0}$ & 66.72 \\
Case wrap angle $/\left(^{\circ}\right)$ & $\varphi_{0}$ & 343 \\
\hline
\end{tabular}




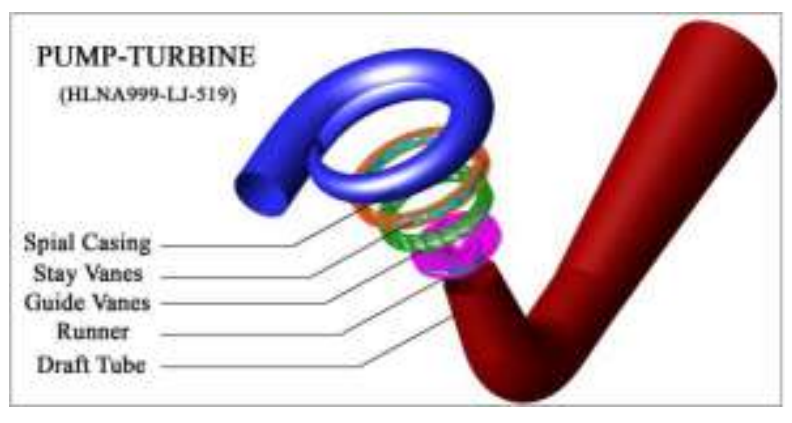

Fig.1Computational domain of pump-turbine model

\subsection{Mesh discretizing}

Considering the conditions in off-design, the flow of the runner inlet is asymmetric, the whole flow passage should be simulated, and the whole computational domain should be divided into grids. In order to ensure fewer calculations and achieving higher calculation accuracy, hexahedral meshes are used. Also, encrypted boundary layers on the walls of blades, volutes, and guide vanes, the mesh size is selected to satisfies the requirements ( $y+$, as shown in Fig.2(b)) of the turbulence model. Fig 2. Left: Mesh pattern of model pump-turbine.The number of meshes in each part is shown in Table 2 .

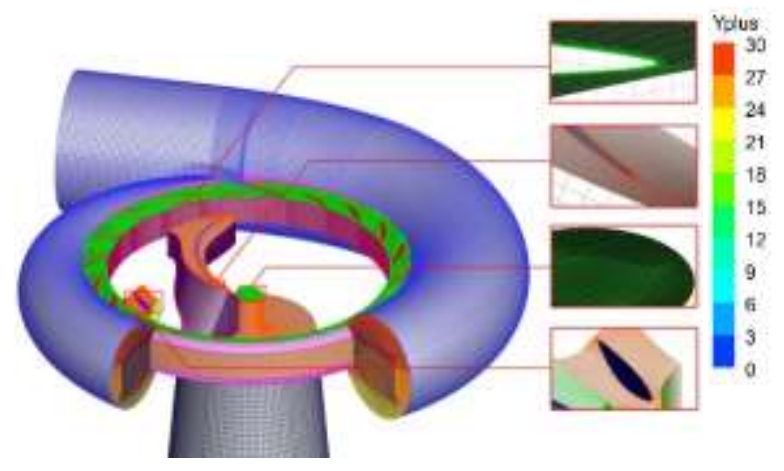

(a)

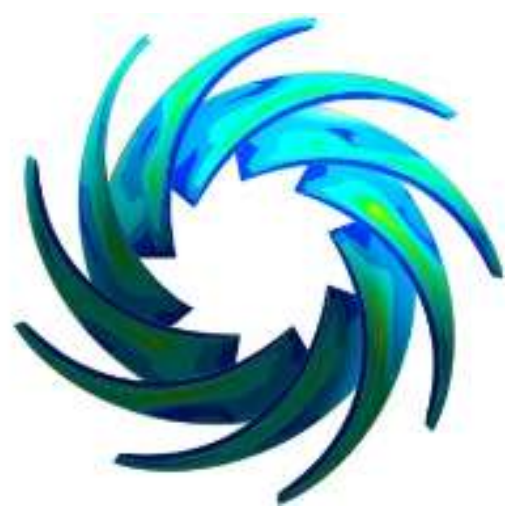

(b)

Fig. 2Mesh pattern of model pump-turbine. (a) Whole configuration mesh; (b) $\mathrm{Y}^{+}$distribution of blade

Tab. 2 The grid division of each part

\begin{tabular}{ccccc}
\hline Parameter & Spial Casing \& Stay vane & Guide vane & Runner & Draft tube \\
\hline Total elements & 1794767 & 1118500 & 1205507 & 1456365 \\
Total nodes & 316840 & 1028400 & 1127820 & 1422144 \\
Min angle $/\left(^{\circ}\right)$ & 18 & 29 & 30 & 36 \\
Min quality & 0.50 & 0.48 & 0.50 & 0.65 \\
\hline
\end{tabular}

\subsection{Turbulence models and boundary conditions}

The finite volume method is used to solve the Reynolds-averaged Navier-Stokes equations. The turbulence model, three turbulence model, SST (shear stress transport) $k-\omega$ and Realizable $k-\varepsilon$ are chosen for the simulations and 
comparison. Select operating point OP.1 and OP.2; the calculation results are shown in Table 3. Compared with the different turbulence models, the Realizable $k-\varepsilon$ turbulence model has the smallest error. Also, the realizable $k-\varepsilon$ model can better simulate the vortex near the wall. Also, realizable $k-\varepsilon$ turbulence model can effectively simulate the shear flow, which includes jet flow, mixed flow, and separated flow [18-20]. Above all, in this study, the Realizable $k-\varepsilon$ was selected for numerical calculation. The boundary conditions are shown in Table 4.

Tab.3 Comparison between simulation and test result. $\left(Q_{s 11}\right.$ is the unit flow of simulation, $n_{s 11}$ is unit speed of simulation, $Q_{t 11}$ is the unit flow of experimental test, $n_{t 11}$ is the unit speed of experimental test.)

\begin{tabular}{cccccccc}
\hline Condition & Turbulence & $Q_{\mathrm{s} 11} /$ & $n_{s 11} /(\mathrm{r} / \mathrm{min}$ & $Q_{\mathrm{t} 11} /$ & $n_{\mathrm{t} 11} /(\mathrm{r} / \mathrm{min}$ & $\Delta Q_{11} /$ & $\Delta n_{11} /(\mathrm{r} / \mathrm{min}$ \\
\hline \multirow{3}{*}{ OP.1 } & Realizable $k-\varepsilon$ & 0.150 & 57.61 & 0.152 & 57.623 & 1.32 & 0.02 \\
& Standard $k-\omega$ & 0.147 & 55.20. & 0.152 & 57.623 & 3.29 & 4.20 \\
& SST $k-\omega$ & 0.149 & 56.90 & 0.152 & 57.623 & 1.97 & 2.99 \\
\hline \multirow{3}{*}{ OP.2 } & Realizable $k-\varepsilon$ & 0.271 & 65.3 & 0.276 & 66.217 & 1.81 & 1.38 \\
& Standard $k-\omega$ & 0.274 & 64.08 & 0.276 & 66.217 & 0.72 & 3.23 \\
& SST $k-\omega$ & 0.266 & 64.30 & 0.276 & 66.217 & 3.62 & 2.90 \\
\hline
\end{tabular}

It can capture the turbulent diffusion at multiple scales and improve the calculation accuracy. Consequently, the flow governing equation groups with the Realizable k-\&model are selected as follows.

Reynolds equation:

$$
\frac{\partial\left(\rho u_{i}\right)}{\partial t}+\frac{\partial\left(\rho \overline{u_{i} u_{j}}\right)}{\partial x_{j}}=-\frac{\partial p}{\partial x_{i}}+\frac{\partial}{\partial x_{j}}\left(\mu \frac{\partial u_{i}}{\partial x_{j}}-\rho \overline{u_{i} u_{j}}\right)+S_{i}
$$

Continuity equation:

$$
\frac{\partial \rho}{\partial t}+\frac{\partial(\rho u)}{\partial x}+\frac{\partial(\rho v)}{\partial y}+\frac{\partial(\rho w)}{\partial z}=0
$$

$k$ equation

$$
\frac{\partial(\rho k)}{\partial t}+\frac{\partial\left(\rho k u_{i}\right)}{\partial x_{i}}=\frac{\partial}{\partial x_{j}}\left[\left(\mu+\frac{\mu_{t}}{\sigma_{k}}\right) \frac{\partial k}{\partial x_{j}}\right]+G_{k}-\rho \varepsilon
$$

$\varepsilon$ equation:

$$
\frac{\partial(\rho \varepsilon)}{\partial t}+\frac{\partial\left(\rho \varepsilon u_{i}\right)}{\partial x_{i}}=\frac{\partial}{\partial x_{j}}\left[\left(\mu+\frac{\mu_{t}}{\sigma_{\varepsilon}}\right) \frac{\partial \varepsilon}{\partial x_{j}}\right]+\rho C_{1} E \varepsilon-\rho C_{2} \frac{\varepsilon^{2}}{k+\sqrt{v \varepsilon}}
$$

where $\rho$ is density, $\mu_{\mathrm{i}}$ is effective viscosity, $k$ is turbulent kinetic energy, $\varepsilon$ is turbulent dissipation rate.

The SIMPLEC algorithm was used in conjunction with the Realizable $\mathrm{k}-\varepsilon$ turbulence model to solve the three-dimensional Navier-Stokes equations in implicit formulation.

Tab.4 Boundary conditions

\begin{tabular}{cc}
\hline Boundary condition type & Boundary condition settings \\
\hline Inlet & Mass flow rate \\
Outlet & Outflow \\
Interface & Mesh Interface \\
Near-Wall Treatment & No Slip、Standard Wall function
\end{tabular}




\subsection{Time Step}

In order to accurately capture the evolution of the vortexs, the time step of the numerical calculation should be set small enough.So the time step of this paper is set to 0.0001 s. The convergence result of steady-state calculation is used as the initial condition for unsteady calculations. The maximum number of calculation iteration steps in each time step is set to 300.At the same time, in order to capture the position of the vortex, a full flow field is saved every two time steps.

\subsection{Experimental validation}

Using the experimental platform of the State Key Laboratory of Hydropower Equipment (Harbin Institute of Large Electrical Machinery China), the evolution of channel vortex was studied. Test hydraulic head $\left(H_{\mathrm{m}}=30 \mathrm{~m}\right)$ is determined by measuring the pressure difference between the inlet and outlet[21].Test-sets, as shown in Fig.3, is a closed cycle system and can be operated in both directions. The test parameters are shown in Table 5.

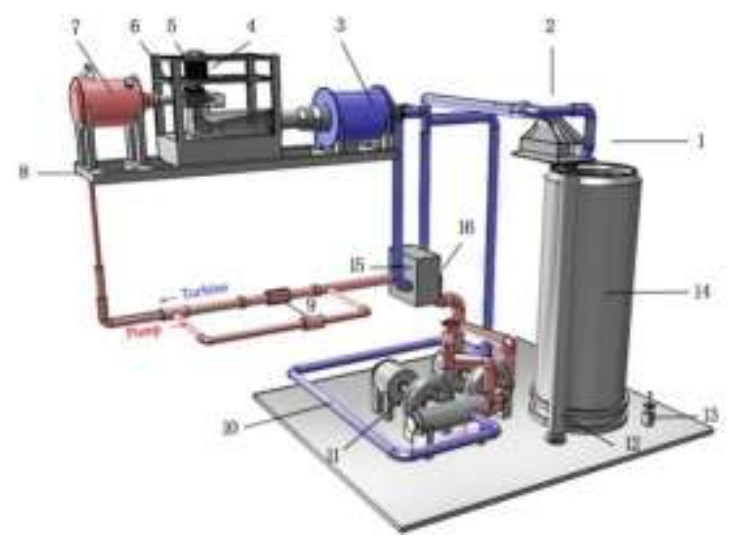

1.Flow board diverter 2Nozzle 3 Low-pressure vessel 4 Dynamometer motor 5 Torque measurement system 6 Pump-turbine model 7 High-pressure vessel 8 Stent 9 Flowmeter 10 Closed system pipeline 11 Pump-turbine 12 Open system pipeline 13 Weighing sensor 14 Weighing cylinder 15 Water cooling system 16 Commutation pipeline

(a)

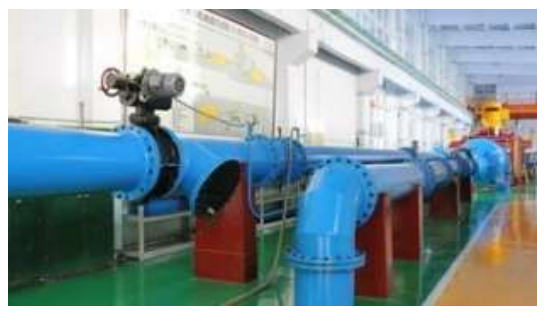

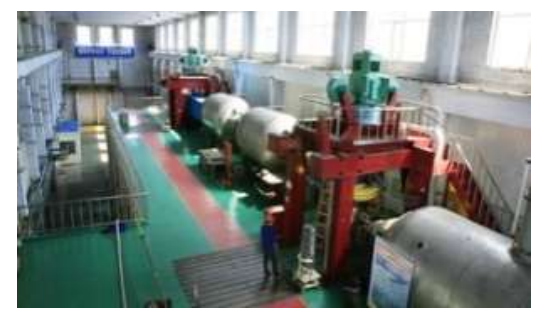

(b)

Fig.3 Sketch of the test bench (a) and the real test bench (b) used for performing tests under the runaway condition A pump-turbine was selected in order to run under the runaway condition, and its main characteristics are listed in Table 5.

Tab.5 The parameters of test-bed 


\begin{tabular}{cc}
\hline Test head maximum $/ \mathrm{m}$ & $190\left(\mathrm{H}_{2} \mathrm{O}\right)$ \\
Mass flow maximum $/\left(\mathrm{m}^{3} / \mathrm{s}\right)$ & 2.0 \\
Runner diameter $/ \mathrm{mm}$ & $300 \sim 500$ \\
Dynamometer power $/ \mathrm{kW}$ & 500 \\
Dynamometer speed / $(\mathrm{r} / \mathrm{min})$ & $0 \sim 2500$ \\
Motor Power of water supply pump / $\mathrm{kW}$ & $600 \times 2$ \\
Flow calibration container volume $/ \mathrm{m}^{3}$ & $120 \times 2$ \\
Reservoirvolume $/ \mathrm{m}^{3}$ & 750 \\
\hline
\end{tabular}

Laboratory tests were performed in order to study the performance of pump-turbine running in a runaway condition. Table 6 shows the main characteristics of the main components used laboratory test.

The seven different operating points on the runaway condition line is selected and simulated by CFD. Through the comparison of experiments and simulations, it is verified whether the calculation model and calculation method are reliable. As shown in Table 6, the rotation speed $(n)$ and the inlet mass flow rate $\left(q_{m}\right)$ were calculated based on the test data and set calculation parameters.

Tab.6 Numerical simulation results of steady flow

\begin{tabular}{ccccc}
\hline $\mathrm{A}_{0} / \mathrm{mm}$ & $n_{11} /(\mathrm{r} / \mathrm{min})$ & $Q_{11} /\left(\mathrm{m}^{3} / \mathrm{s}\right)$ & $n /(\mathrm{r} / \mathrm{min})$ & $q_{\mathrm{m}} /(\mathrm{kg} / \mathrm{s})$ \\
\hline 11 & 57.61 & 0.150 & 1051.810 & 73.943 \\
19 & 62.30 & 0.215 & 1137.436 & 105.984 \\
21 & 64.74 & 0.249 & 1182.015 & 122.690 \\
25 & 66.26 & 0.276 & 1209.762 & 135.835 \\
33 & 70.82 & 0.376 & 1292.989 & 185.349 \\
41 & 74.47 & 0.511 & 1359.595 & 251.952 \\
45 & 76.52 & 0.545 & 1397.056 & 268.658 \\
\hline \multicolumn{5}{c}{$n_{11}=\frac{n D_{2}}{\sqrt{H}}$} \\
& $Q_{11}=\frac{Q}{D_{2}^{2} \sqrt{H}}$ & & $(5)$ \\
& & &
\end{tabular}

Where $\boldsymbol{n}$ is the rotational speed, $\mathrm{r} / \mathrm{min} ; \boldsymbol{D}_{2}$ is the nominal diameter of Runner, $\mathrm{m} ; \boldsymbol{Q}$ is the calculated flow, $\mathrm{m}^{3} / \mathrm{s}$;

Calculate the head $(\mathrm{H} / \mathrm{m})$ and obtain the unit discharge $Q_{11}$ and unit rota (rotation) speed $n_{11}$ by using Eq. (5)、 (6).Comparing the simulated with the experimental, the results are shown in Fig 4(a). The experimental results agree well with the numerical simulation results. Meanwhile compared simulated cloud image of the vortex with the experimental photograph, the simulation results are in good agreement with the experimental results. Those prove that the numerical simulation method can better reflect the real flow inside the runner, and the simulation method is accurate and reliable. 


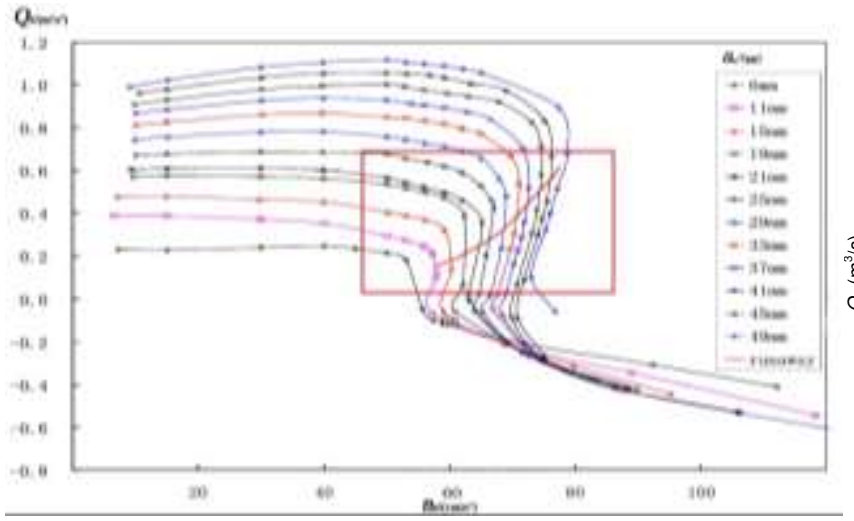

(a)

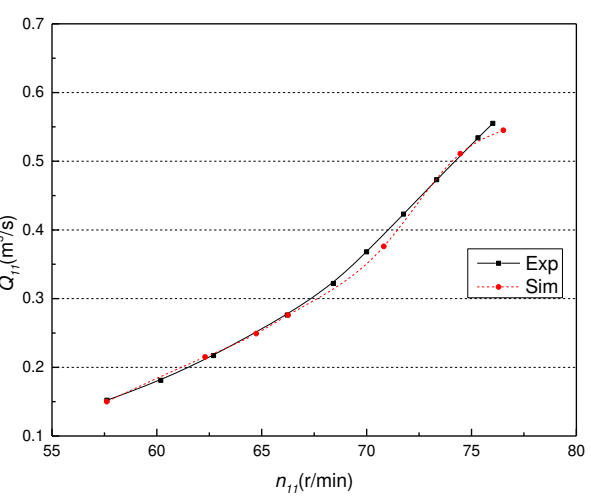

(b)

Fig. 4 Comparison of calculated and experimental results

Figure (a) shows the results of all conditions obtained in the experiment, and the red rectangle marks the runaway conditions. The figure (b) shows the variation $n_{11}$ and $Q_{11}$, where $n_{11}$ is the unit rota speed, r/min; $Q_{11}$ is unit discharge $\mathrm{m}^{3} / \mathrm{s}$; (- •- experimental data results, and (-- --)numerical simulation results.

\section{Results and discussion}

In the runaway condition, different scale vortex is distributed in the runner-zone. We call it a coherent structure with a larger, relatively regular vortex structure on the other scales. As shown in Figs.5, we can discover that different scale coherent structures are distributed in each runner channel. In order to study the evolution of the coherent structure more clearly, the channel is divided as shown in Fig 5, and the rotation angle of the runner area is corrected to ensure that the blades are relatively stationary.

In the small flow condition of runaway, the unsteady calculation, it can be found that the coherent structures are near the suction surface of the blade. As shown in Fig 5, the coherent structure is also found in the position of the blade inlet. So the coherent structure can be divided into the outlet of the blade, the blade inlet and the middle of the blade channel three parts by their distribution position.

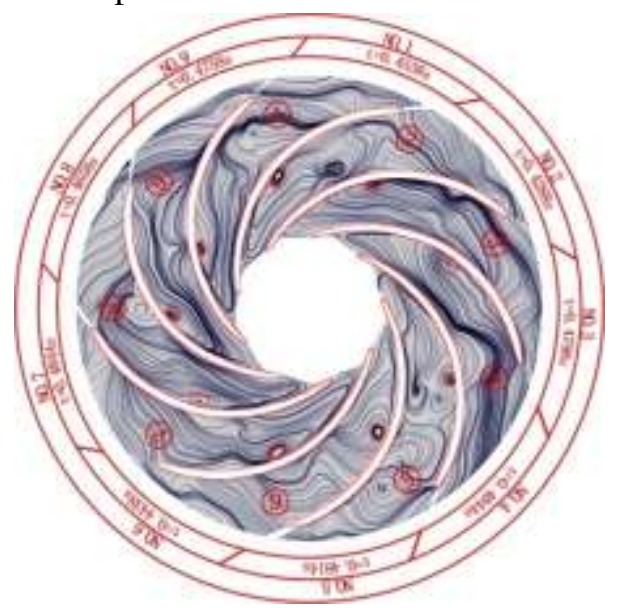

Fig. 5The number of blade channels and channel vortices at different times 
No.1- No.9 are the data at time $\mathrm{t}=0.4538 \mathrm{~s}, 0.4288 \mathrm{~s}, 0.4798 \mathrm{~s}, 0.4844 \mathrm{~s}, 0.4814 \mathrm{~s}, 0.4438 \mathrm{~s}, 0.4844 \mathrm{~s}, 0.4538 \mathrm{~s}$, $0.4658 \mathrm{~s}, 0.4758 \mathrm{~s}$. At these moments, vortices appear in the middle of the blade.The position of the vortex in the picture has been calibrated with a red circle.

\subsection{Evolution of the coherent structure at the blade outlet}

In order to further study the evolution rule of the coherent structure at the outlet of the blade, the streamline chart of the one channel is selected as shown in Fig 6. It shows that the coherent structure moves along the wall from the outlet of the channel to middle with stretching and contraction. Because the fluid element in the instantaneous state of each point can be decomposed into three directions, they are the translation, expansion along the principal axis (It can be decomposed for the uniform expansion and pure deformation) and the rigid rotation around an axis. The incompressible fluid element is subjected to the maximum tensile force in the direction of the wall in the direction of $\pi / 4$ (The flow direction is positive), and the maximum contraction in the direction of $3 \pi / 4$. Because of the velocity difference at the trailing edge position, the flow field is subjected to shearing action, and the adhesion condition makes it generate vorticity. At the same time, it is accompanied by a translation and stretching along the wall $\pi / 4$ direction.

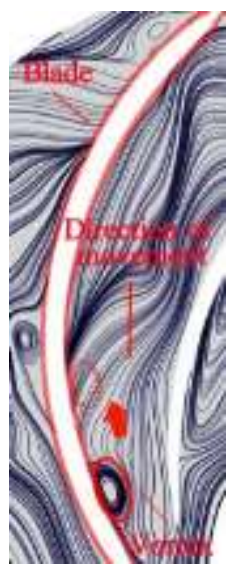

(a) $\mathrm{t}=0.4364 \mathrm{~s}$

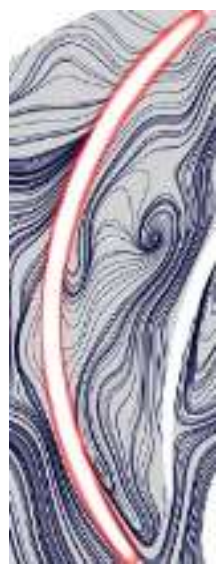

(b) $\mathrm{t}=0.4294 \mathrm{~s}$

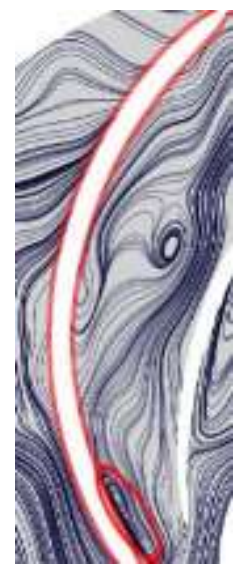

(c) $\mathrm{t}=0.4310 \mathrm{~s}$

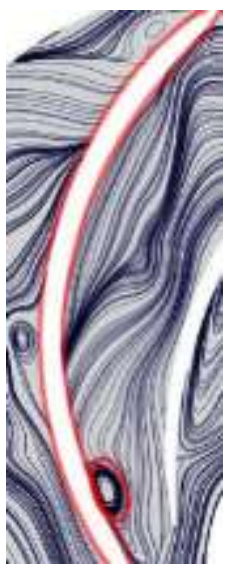

$(\mathrm{d}) \mathrm{t}=0.4366 \mathrm{~s}$

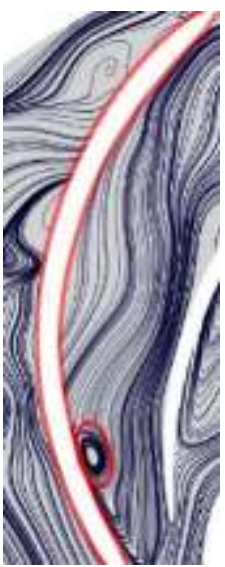

(e) $t=0.4426 \mathrm{~s}$

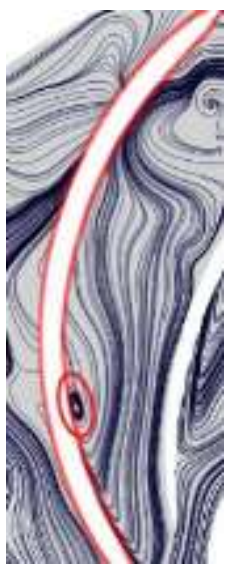

(f) $\mathrm{t}=0.4538 \mathrm{~s}$

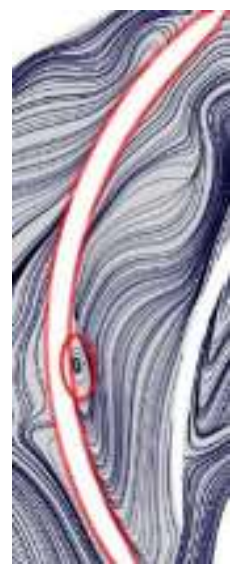

(g) $\mathrm{t}=0.4698 \mathrm{~s}$

Fig.6 Channel(No.1 blade channel) snapshot of the evolution of the vortex in one cycle.

\subsection{Influence of vortex structure at blade suction side on blade pressure load}

The pressure load distribution in the single vortex evolution period of blade no. 2 was taken. Figure 7 indicates that the pressure load on the suction side of the blade decreases along the direction of the blade inlet and the peaks appear at the inlet and outlet of the blade, respectively,shown ax Figure 7. Local high-pressure area and local low-pressure area appear in the blade outlet section, respectively. With the development of the vortex cycle, the peak position of the local high-pressure area does not change, and the position of local low-pressure area moves towards the inlet of the blade with time corresponding to the vortex movement on the suction side of the blade. Compared to the change of the minimum low pressure in the local low-pressure area with time: local low pressure does not exist in the initial vortex stage (Fig7a). Local low-pressure areas appear at corresponding positions with the moving blade loads of vortices. The minimum pressure value in the low-pressure area decreases, and the low-pressure area becomes more apparent. As time goes on, the position of the low-pressure area moves towards the blade inlet, and the minimum pressure gradually increases. The low-pressure area gradually becomes less noticeable and disappears with the disappearance of the vortex movement. This indicates that the vortex changes the pressure load distribution of the runner blade during the development process. Low pressure is generated locally at the vortex development location of the runner blade and the location of the low-pressure area changes with the 
displacement and intensity of the vortex. Compared to the local low-pressure area, the location of the local high-pressure area and the peak value did not change. The generating location of the local high-pressure area is the same as the generating location of discharge cone turbulence at the outlet of the runner blade. Therefore, the local high-pressure zone is caused by the collision turbulence between the outlet of the runner blade and the drainage cone.
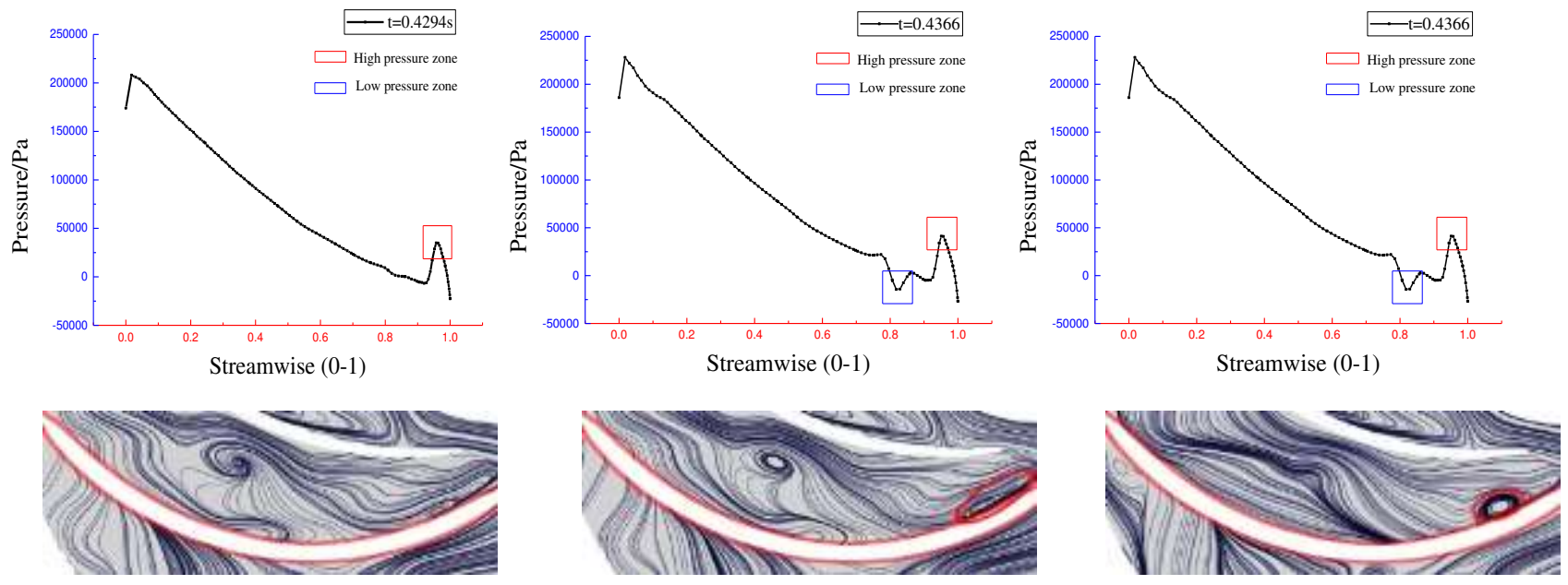

(a) $t=0.4294 \mathrm{~s}$

(b) $\mathrm{t}=0.4310 \mathrm{~s}$

(c) $\mathrm{t}=0.4366 \mathrm{~s}$
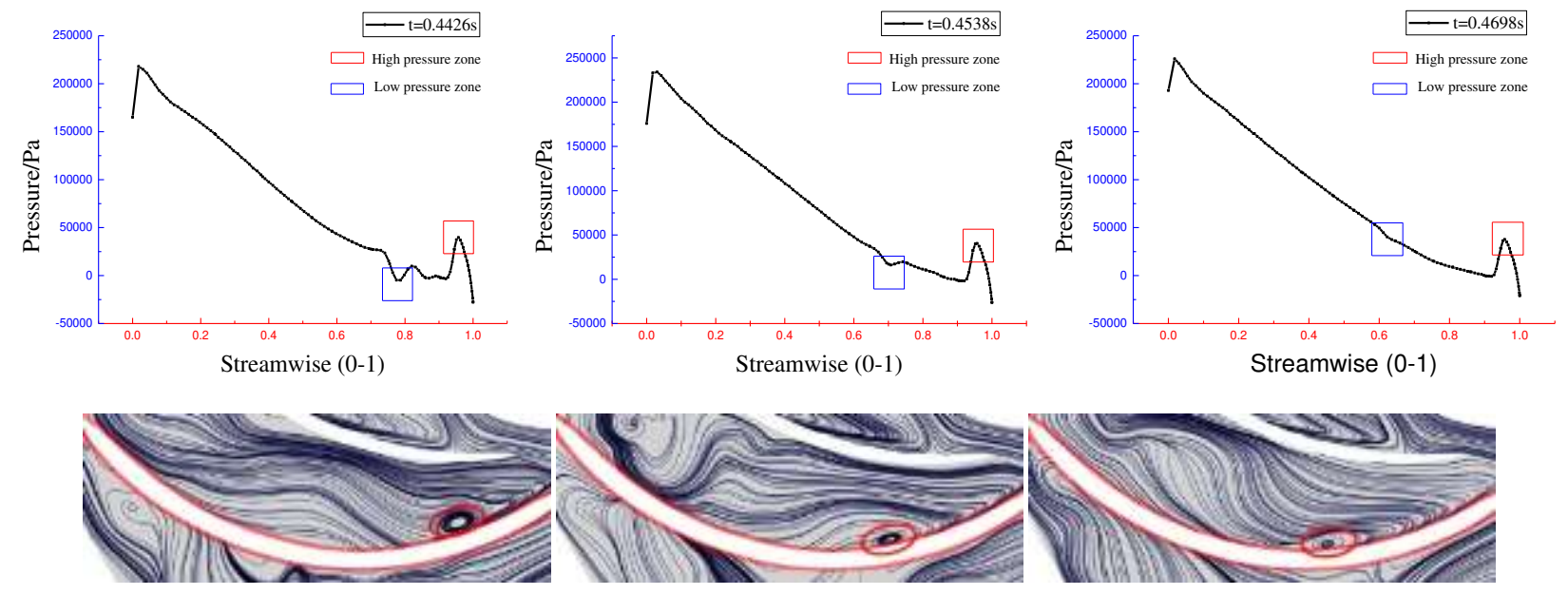

(d) $t=0.4426 \mathrm{~s}$

(e) $\mathrm{t}=0.4538 \mathrm{~s}$

(f) $t=0.4698 \mathrm{~s}$

Fig.7 Blade pressure load distribution

The blade pressure load, pressure (y-axis direction) and streamwise (0-1) is the relative position of the blade(x-axis direction);High pressure areas are marked with a red rectangular frame and low pressure areas are marked with a blue rectangular frame. The insets show the corresponding instantaneous snapshots of the streamline of velocity fields near the centre of the blade plate. The position of the vortex is marked by red oval.

In order to obtain the evolution process and characteristics of the coherent structure on the suction surface of the blade, a tangential velocity distribution map is made at the birth position and time of the vortex, as shown in Fig.8(a). At the time of Fig 6 (d), the vorticity iso-surface is obtained, and the three-dimensional vortex structure map is obtained, as shown in Fig. 9. 
From the tangential velocity distribution of Fig 8 (b), we can discover that the effect of the fluid on the outlet of the blade is determined by the shear flow. It is a flow pattern similar to a wall jet, judging from the law of velocity distribution. As shown in Fig 10, it can be found that the jet is mainly caused by the large angular velocity of the runner and the sizeable centrifugal force. With the action of centrifugal force, a highspeed rotating fluid is accumulated at the outlet position of the runner blade. The collision between a fluid and a high-speed rotating blade makes it forced to divert at the exit of the blade. As the speed of the runner is larger, the process of the collision between the fluid and the blade is more similar to the wall jet. Thus, a coherent structure is generated at the outlet position of the runner blade.

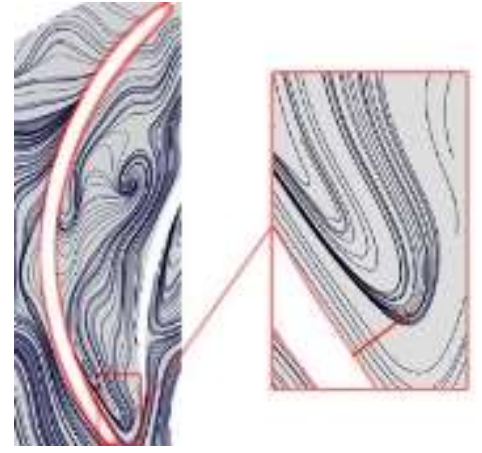

(a)

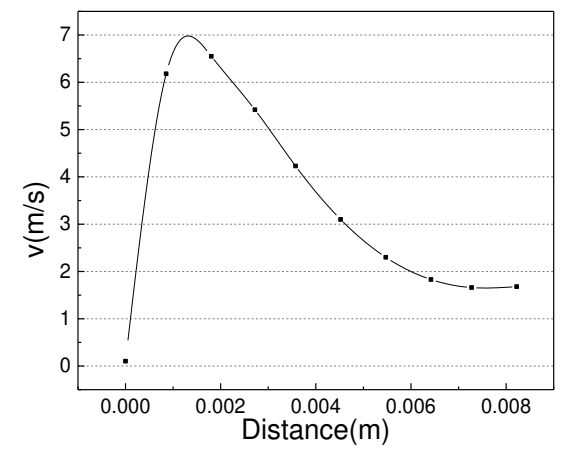

(b)

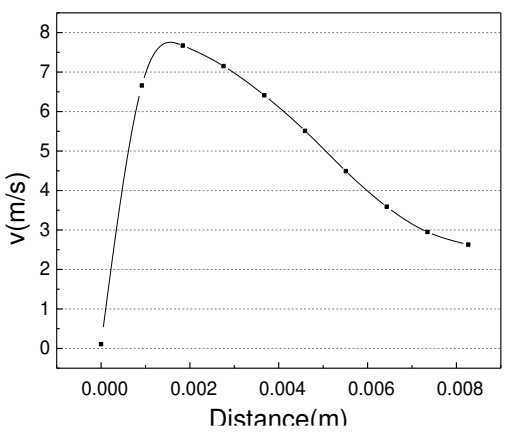

(c)

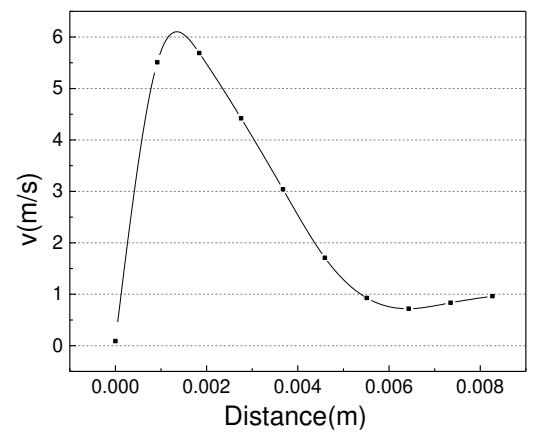

(d)

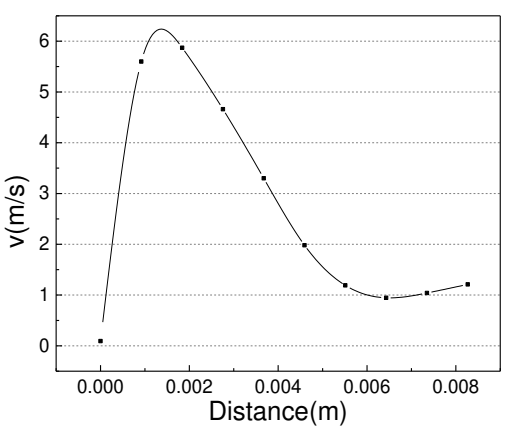

(e)

Fig.8 Tangential velocity distribution

Figure (a) is the location of speed extraction,figure $b$ is the velocity distribution at the mark of figure (a); Figures (b-e) are the velocity distributions of channels NO. 1, 3, 6, and 9 . Cannels number is defined in Figure 5.

From the three-dimensional shape of vorticity iso-surface in Fig. 9, it can be found that the direction of the vortex and the flowing fluid are perpendiculars. Thus, it can be judged that the coherent structure of the rear surface of the rotor blade is a spanwise vortex. It is due to the effect of wall jet shearing on the uneven velocity distribution. When the disturbing wave number is sufficiently large, the shear layer is destabilized, and the vorticity is formed. The inducing effect of the vortex sheet and its further enhancement with the disturbance of the flow from theblade channel make the unstable wave gradually roll up and develop into a periodic spanwise vortex. Since the vorticity of the feed fluid increases parallel to the wall, the vortex moves along the wall surface under the effect of tangential force, and the fluid velocity of the near-wall decreases with the increase of the moving distance. At the same time, due to the influence of the flow from the blade channel, the vortex core is not evenly distributed in the circumferential direction, and the vortex develops to disappear in the middle of the blade. 


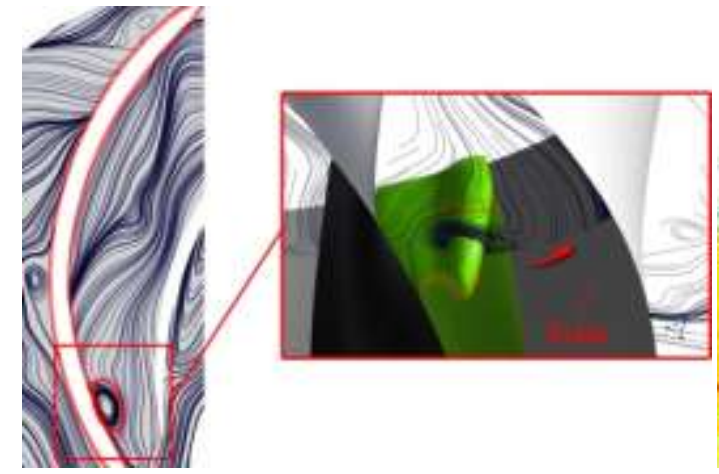

Fig.9Blade spanwise vorticity structure

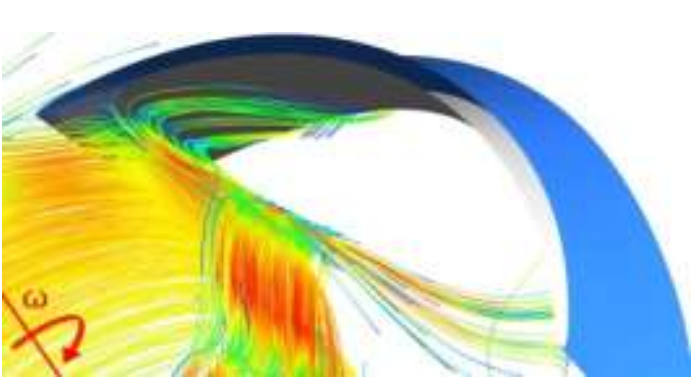

Fig.10 Streamline at the outlet of blade

\subsection{Evolution of coherent structure at the inlet of the blade}

In order to study the effect of the inlet of the blade on the flow pattern and the coherent structure of the blade, the CFD-POST post-processing software was used to turbo-process the runner area under the runaway speed operating condition. From Fig. 11, it is found that vortex moves downstream and then falls, The process of evolution forms a vortex street. In order to clarify the evolution of morphology vortices and their causes, the No. 1 flow channel used to show the velocity streamline diagram, shown as iFig. 11. The vortex begins at the leading edge of the blade inlet, as shown in Fig 12(a). Due to the liftacting, the vortex moves backward along the leading edge of the blade and diffuses into the fluid interior. As the vortex diffuses into the fluid, external disturbances and self-induction of the main vortex cause the vortex layer to stretch, diffuse and dissipate. Twice separation vortex was induced, as shown in Fig. 12(d). The concentrated vortex formed after vortex separation causes a large pressure gradient, which causes the bottom pressure to decrease. The vortex layer in the higher pressure area near the side of the blade wall is pulled into the wake to form a new vortex, and the vortex layer continues to stretch. The vortex layer is stretched, diffused, or even pulled off. Finally, the vortices alternately fall off.

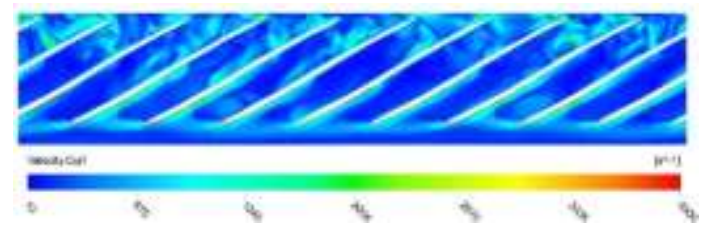

Fig.11Vorticity contour of blade channels

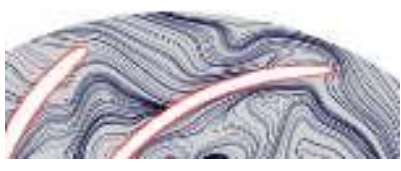

(a) $\mathrm{t}=0.4296 \mathrm{~s}$

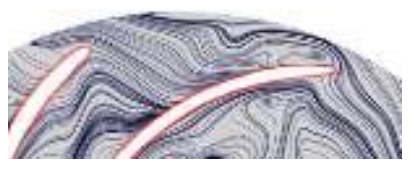

(b) $\mathrm{t}=0.4306 \mathrm{~s}$

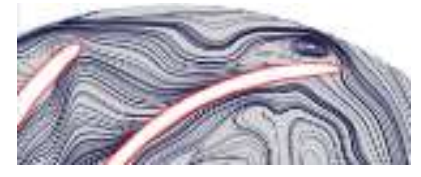

(c) $\mathrm{t}=0.4334 \mathrm{~s}$

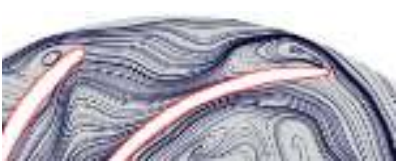

(d) $\mathrm{t}=0.4352 \mathrm{~s}$

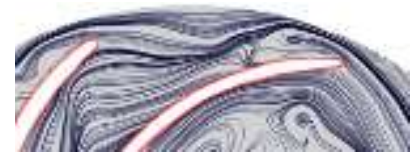

(e) $\mathrm{t}=0.4378 \mathrm{~s}$

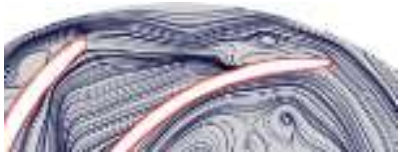

(f) $\mathrm{t}=0.4388 \mathrm{~s}$

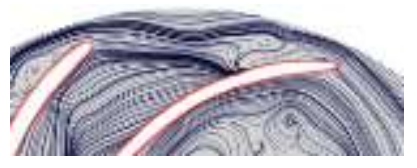

(g) $\mathrm{t}=0.4396 \mathrm{~s}$

Fig.12 Streamline of inlet of blade

To explore the cause of vortices at the inlet of the blade, the attack angle is calculated. According to the contour of the blade, the airfoil bone line was drawn, and the velocity was extracted in the vertical direction of the bone line, as shown in Fig.13(a). Calculate its attack angle, as shown in Fig.13(b).From Fig. 13(b), it can be found that the value of the attack angle is larger.The maximum is $22.5^{\circ}$, and the minimum is $15.6^{\circ}$; in the direction from point $\mathrm{C}$ to point $\mathrm{D}$, 
the attack angle first decreases and then increases. Through the calculation of other channel and conditions, the value of the attack angle is large in each case. So the detailed distribution of the absolute attack angle is shown in Fig. 13(c-e). The distribution is irregular, and no obvious periodicity could be observed.However, it is certain that the large attack angle is responsible for the formation of vortices at the channel inlet.

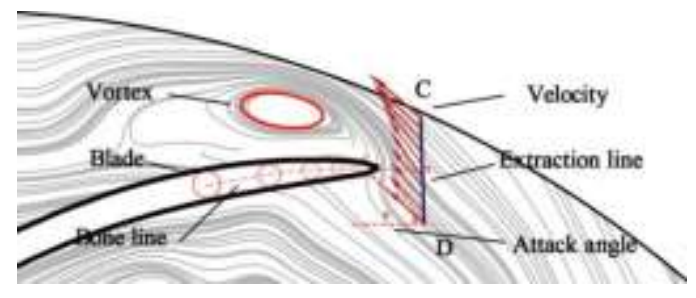

(a)

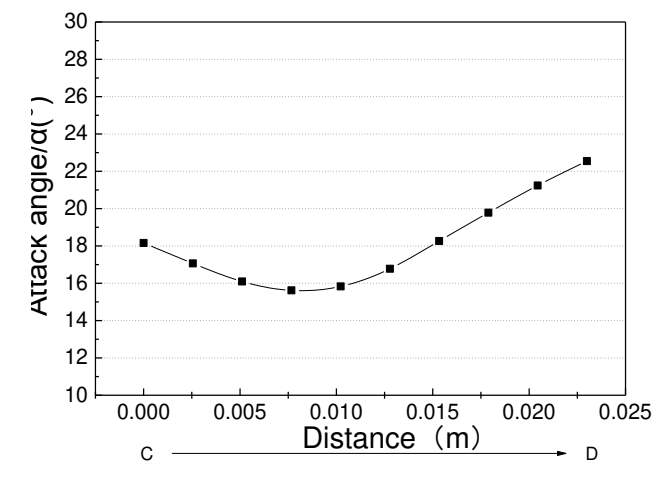

(b)

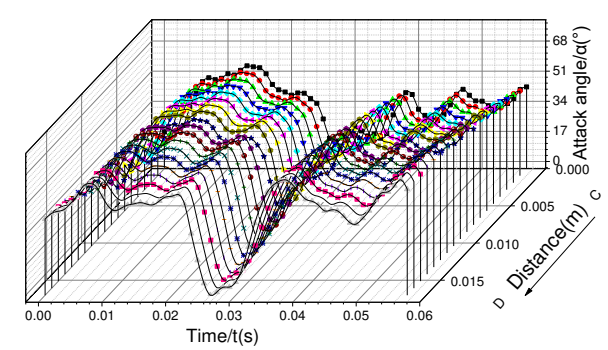

(c)

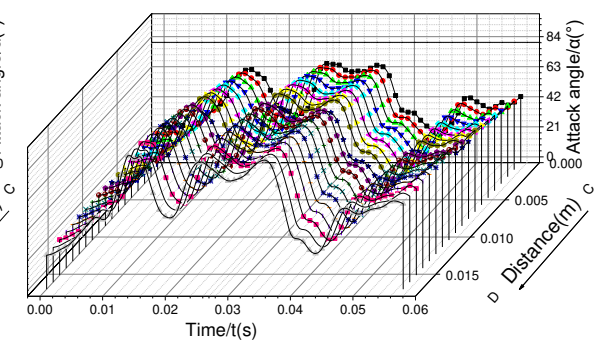

(d)

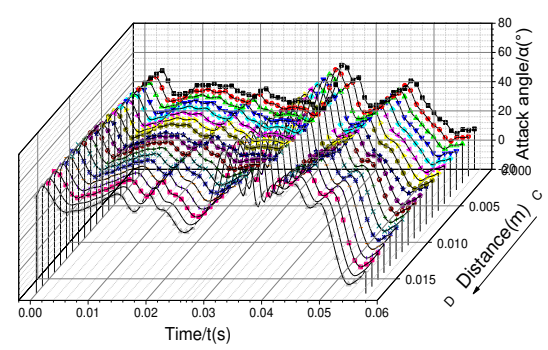

(e)

Fig.13Distribution of attack angle

Figure (a) is the method and position for calculating the attack angle.Figure (b) shows the trend of the attack angle from point $\mathrm{C}$ to point $\mathrm{D}$. Figures (c-e) are the attack angle distribution of channels NO. 3, 6, and 9 . Cannels number is defined in Figure 5.

\subsection{Evolution of coherent structures in runners}

In runaway conditions, different scale vortices are distributed in the middle of the runner channel. In order to study its origin and evolution, the coherent structure of No. 7 runner channel is studied as shown in Fig.14

Fig. 14 show that the formation of the coherent structure in the middle of the channel is related to the disturbance of the incoming flow at the leading edge of the inlet end of the blade and the jet formed by the impact of the outlet end of the blade and the fluid. As shown in Fig. 14(a), the leaflet flow at No. 2 is affected by the leading edge of the blade, and the free shear layer is destabilized, and the vortex structure at No. 2 in Fig. 14(b) is developed and formed. At the same time, the coherent structure developed along the wall surface of the blade near the exit of the blade continues to develop upstream as shown in Fig 14(b) No. 1 With the vortex at No. 1 gradually approaching the vortex at No. 2, the 
vortex layer at position No. 3 is changed to generate a vortex structure, as shown in the position of No. 3 in Fig. 14(c). With the development of the structures of No. 1 and No. 3, the vortex at No. 4 is disturbed by the vortex layers. So the vortices at No. 4 and No. 1 form a vertical pair, and the vortices at No. 2 and No. 3 form a vertical pair, as shown in Fig. 14(d). As the vortex at No. 1 continues to develop upstream of the runner, the vortex at No. 4 is "captured" by the No. 1 vortex, and the vortex at No. 1 gains a vortex that is opposite to its own vorticity, counteracting its own vorticity. As shown in Fig 14 (e). Due to the disturbance and self-induction between the vortex layers, the vortices at the No. 1 and No. 3 positions are destabilized and collapsed, and the runner channels return to the original flow state again, as shown in Fig. 14(f-g). The main reason for the formation of the coherent structure in the middle of the leaf passage is that the vortex at the No. 1 position moves along the upstream vortex of the blade and the disturbance of the incoming flow from the leading edge of the blade inlet.

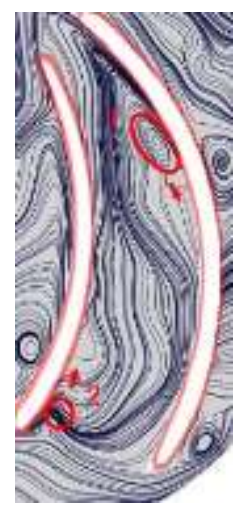

(a) $\mathrm{t}=0.4420 \mathrm{~s}$

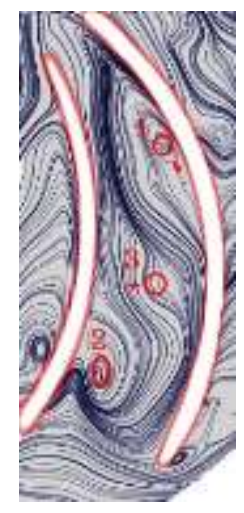

(b) $\mathrm{t}=0.4450 \mathrm{~s}$

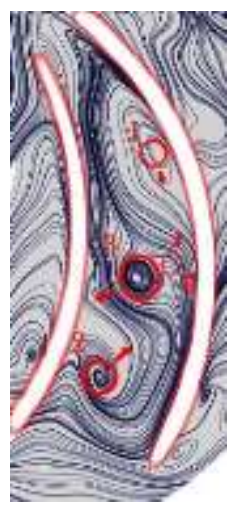

(c) $\mathrm{t}=0.4470 \mathrm{~s}$

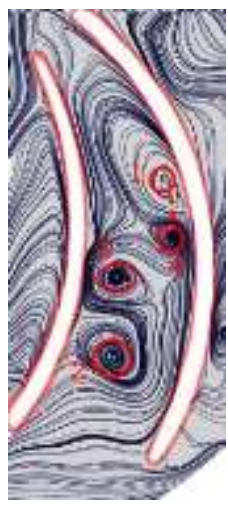

(d) $\mathrm{t}=0.4530 \mathrm{~s}$

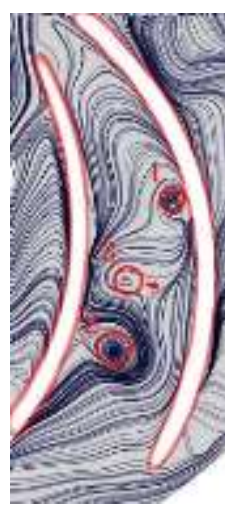

(e) $\mathrm{t}=0.4552 \mathrm{~s}$

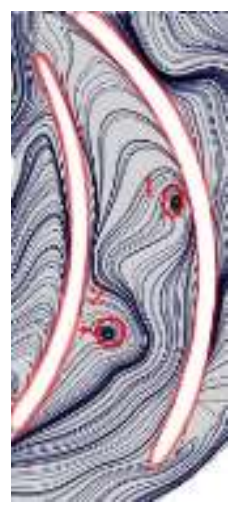

(f) $t=0.4582 \mathrm{~s}$

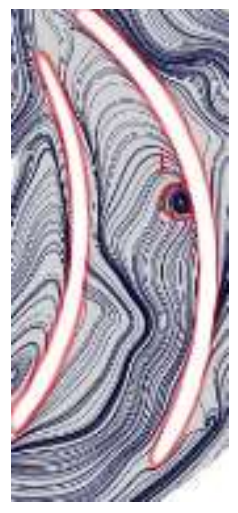

(g) $\mathrm{t}=0.4618 \mathrm{~s}$

Fig.14Evolution of coherent structure in the middle of the blade channel

\section{Conclusions}

The transient for runaway condition is simulated and analyzed in this paper using Realizable $k-\varepsilon$ turbulence model. From the results, the following conclusions are drawn:

(1) In the case of the small flow rate in runaway operation, the spanwise vortex structure is formed by the collides between the tail wall of the and the counter-rotating fluid, and it moves along the suction surface of the vane and enters to the upstream of the runner channel, resulting in the formation of more vortex structures in the runner area. These vortex structures affect the distribution of the blade pressure load. (2) At the small flow rate in runaway state, the speed of the runner is quite high, the direction of flow and the bone line of the blade form a large attack angle. The large scale vortex appears on the position of the pressure surface near the inlet of blade. Thus under non-design conditions, large attack angle is the main cause of vortex formation.

(3) The formation and evolution of the coherent structure in the middle position of the channel are mainly influenced by bidirectional action between the downstream flow state at the outlet of the blade near the suction surface and the runner cone and the incoming flow state at the leading edge of the blade.

\section{List of Abbreviations}

Abbreviations is not used. 


\section{Availability of data and materials}

Data sharing is not applicable to this article as no datasets were generated or analyzed during the current study.

\section{Competing interests}

The authors declare that they have no competing interests.

\section{Funding}

This project is supported by National Natural Science Foundation of China (Grant No. 52066011). The authors thank State Key Laboratory of Hydropower Equipment (Harbin Institute of Large Electrical Machinery China).Sichuan Key Laboratory of Fluid Machinery and Engineering(Grant No.szjj2019-025).

\section{Authors' Contributions}

Q. Li proposes the innovation ideas and theoretical analysis, and F. Zhou carries out experiments and data analysis. C. Zhao conceived of the study, and participated in its design and coordination and helped to draft the manuscript. All authors read and approved the final manuscript.

\section{Publisher's Note}

Springer Nature remains neutral with regard to jurisdictional claims in published maps and institutional affiliations.

\section{Author details}

${ }^{1}$ College of Energy and Power Engineering, Lanzhou University of Technology, Lanzhou 730050, P. R. China

${ }^{2}$ State Key Laboratory of Gansu Fluid Machinery and Systems, Lanzhou University of Technology, Lanzhou 730050, P. R. China

\section{References}

[1] Li, D., Wang, H., Qin, Y., Li, Z., Wei, X., \& Qin, D. Mechanism of high amplitude low frequency fluctuations in a pump-turbine in pump mode. Renewable Energy, 126. (2018)

[2] Zhang, Y., Zheng, X., Li, J., \& Du, X. Experimental study on the vibrational performance and its physical origins of a prototype reversible pump turbine in the pumped hydro energy storage power station. Renewable Energy (2018)

[3] Fu, X., Li, D., Wang, H., Zhang, G., Li, Z., \& Wei, X. Influence of the clearance flow on the load rejection process in a pump-turbine. Renewable Energy, 127 (2018)

[4] Yang, J., Pavesi, G., Liu, X., Xie, T., \& Liu, J. Unsteady flow characteristics regarding hump instability in the first stage of a multistage pump-turbine in pump mode. Renewable Energy, 127 (2018)

[5] Li, C., \& Zhou, J. Parameters identification of hydraulic turbine governing system using improved gravitational search algorithm. Energy Conversion \& Management, 52(1), 374-381 (2011)

[6] Hasmatuchi, V., Farhat, M., Roth, S., Botero, F., \& Avellan, F. Experimental evidence of rotating stall in a pump-turbine at off-design conditions in generating mode. Journal of Fluids Engineering, 133(5), 623-635 (2011).

[7] Li, D. Y., Han, L., Wang, H. J., Gong, R. Z., Wei, X. Z., \& Qin, D. Q. Flow characteristics prediction in pump mode of a pump-turbine using large eddy simulation. ARCHIVE Proceedings of the Institution of Mechanical 
Engineers Part E Journal of Process Mechanical Engineering 1989-1996 (2016)

[8] Shi Q H, Xu W W, \& Gong L. Noise caused by vane vortex of low head Francis turbine and its elimination. The Proceedings of the 16th China Hydropower equipment Colloquium, 1-8 (2007)

[9] Zhang P, Zhu B S, \& Zhang L F. Numerical study on Vortex pressure fluctuation in Runner area of Francis Turbine. Large motor technology (6), 35-38 (2009)

[10] Li W. Study on the Vortex Simulation inside the Runner of Medium-specific Speed Francis Turbine. (Doctoral dissertation, University of West China) (2010)

[11] Hasmatuchi V, Roth S, Botero F, et al. High-speed flow visualization in a pump-turbine under off-design operating conditions. IOP Conf. Series: Earth and Environmental Science 12 (2010)

[12] Hasmatuchi, V., Roth, S., Botero, F., Avellan, F., \& Farhat, M. High-speed flow visualization in a pump-turbine under off-design operating conditions. , 12(1), 103 (2010)

[13] Nicolet C, Alligné S, Kawkabani B, et al. Stability Study of Francis Pump-Turbine at Runaway. 3rd IAHR International Meeting of the Workgroup on Cavitation and Dynamic Problems in Hydraulic Machinery and Systems. 2009, Brno, Czech Republic. (2009)

[14] Nicolet C, Alligné S, Kawkabani B, et al. Unstable Operation of Francis Pump-Turbine at Runaway: Rigid and Elastic Water Column Oscillation Modes[J]. 24th Symposium on Hydraulic Machinery and Systems. 2009, Foz do Iguaçu, Brazil. (2009)

[15] Guo L, Liu J T, Wang L Q, et al. Numerical analysis on pump-turbine runaway points. IOP Conf. Series: Earth and Environmental Science 15042017 (2012)

[16] Xia L S, Cheng Y G, You J F, et al. CFD Analysis of the Runaway Stability of a Model Pump-Turbine. IOP Conf. Series: Earth and Environmental Science 49042004 (2016)

[17] Zhang X, Cheng Y, Xia L, et al. Looping dynamic characteristics of a pump-turbine in the S-shaped region during runaway[J]. Journal of Fluids Engineering, 138(9). (2016)

[18] Agrawal, K. K., Bhardwaj, M., Misra, R., Agrawal, G. D., \& Bansal, V. Optimization of operating parameters of earth air tunnel heat exchanger for space cooling: taguchi method approach. Geothermal Energy, 6(1),10 (2018)

[19] Peppas, K. P., Tombras, G. S., Stassinakis, A. N., \& Nistazakis, H. E. Improving the availability of terrestrial fso links over log normal atmospheric turbulence channels using dispersive chirped gaussian pulses. Optics \& Laser Technology, 54, 329-334 (2013)

[20] Tian, W., Song, B., \& Mao, Z. Conceptual design and numerical simulations of a vertical axis water turbine used for underwater mooring platforms. International Journal of Naval Architecture \& Ocean Engineering, 5(4), 625-634. (2013)

[21] Liu C. research on cavitation flow characteristics of pump turbine under partial load conditions. (Doctoral dissertation, Lanzhou University of Technology). (2016)

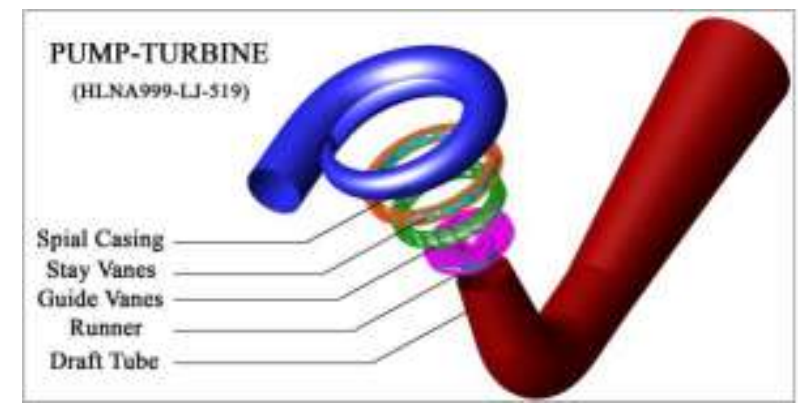


Fig.1Computational domain of pump-turbine model

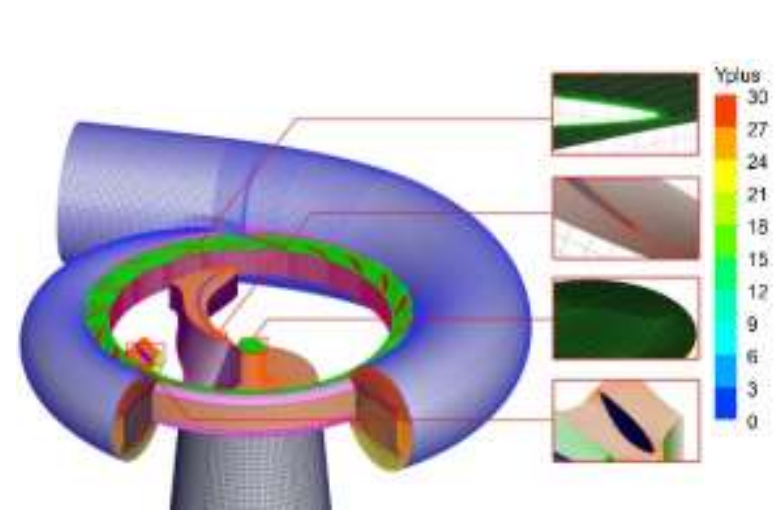

(a)

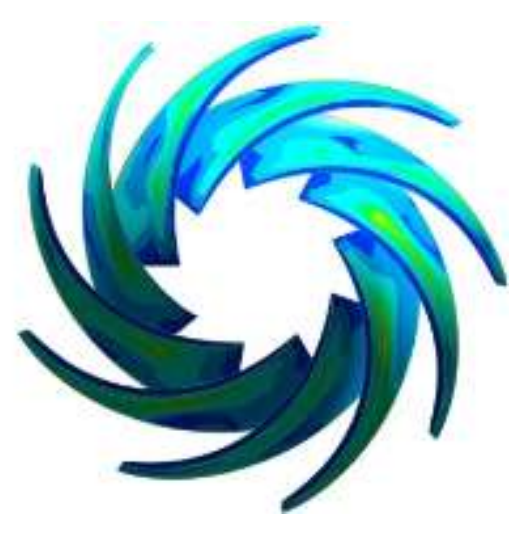

(b)

Fig. 2Mesh pattern of model pump-turbine. (a) Whole configuration mesh; (b) $\mathrm{Y}^{+}$distribution of blade

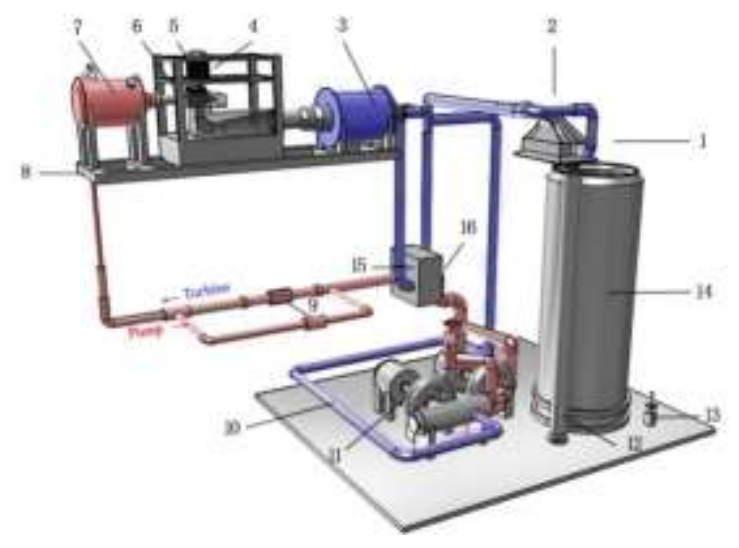

1.Flow board diverter 2Nozzle 3 Low-pressure vessel 4 Dynamometer motor 5 Torque measurement system 6 Pump-turbine model 7 High-pressure vessel 8 Stent 9 Flowmeter 10 Closed system pipeline 11 Pump-turbine 12 Open system pipeline 13 Weighing sensor 14 Weighing cylinder 15 Water cooling system 16 Commutation pipeline

(a)

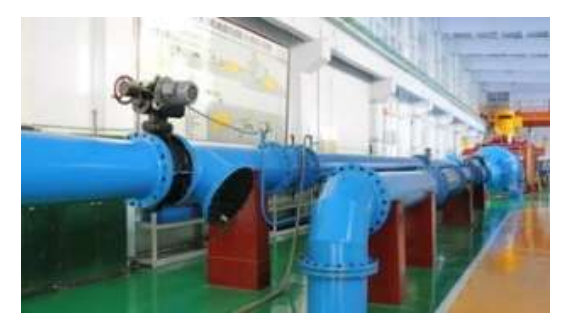

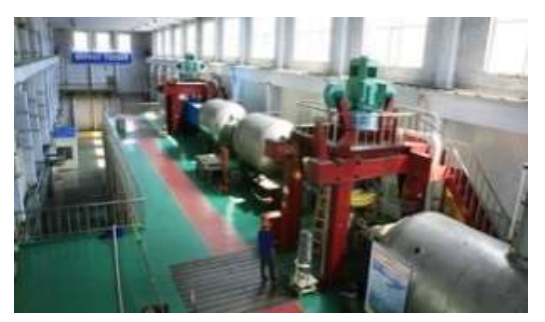

(b) 
Fig.3 Sketch of the test bench (a) and the real test bench (b) used for performing tests under the runaway condition

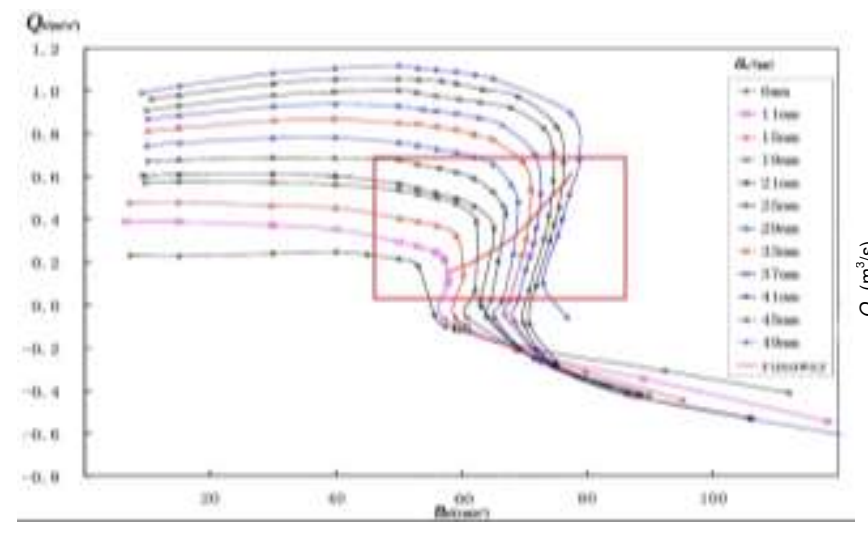

(a)

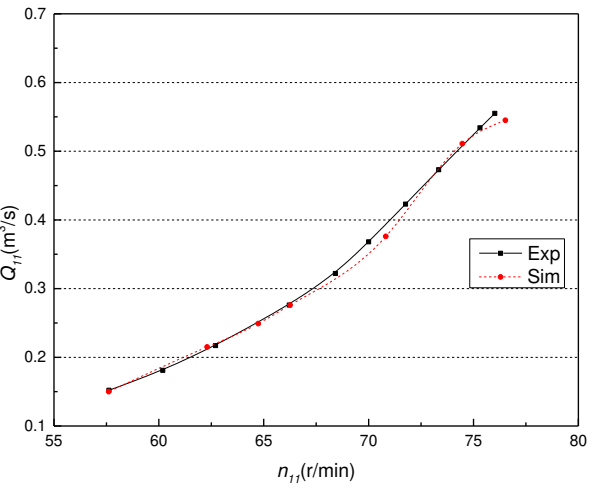

(b)

Fig. 4 Comparison of calculated and experimental results

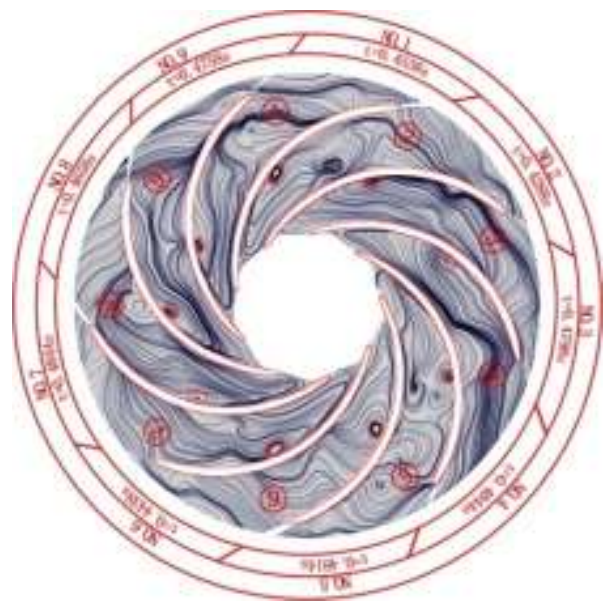

Fig. 5The number of blade channels and channel vortices at different times

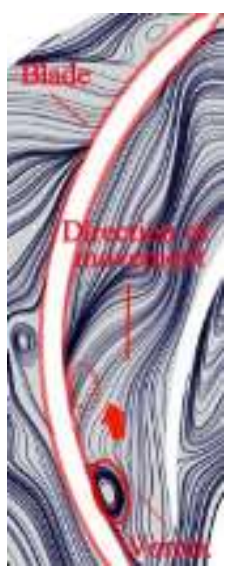

(a) $\mathrm{t}=0.4364 \mathrm{~s}$

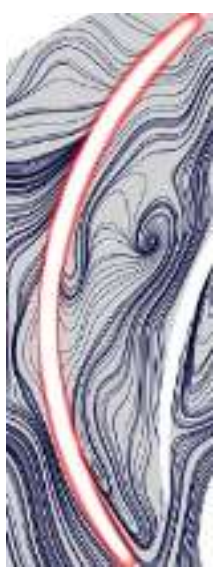

(b) $\mathrm{t}=0.4294 \mathrm{~s}$

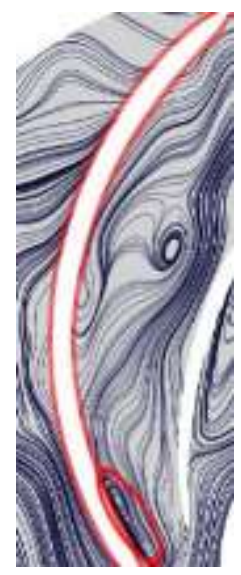

(c) $\mathrm{t}=0.4310 \mathrm{~s}$

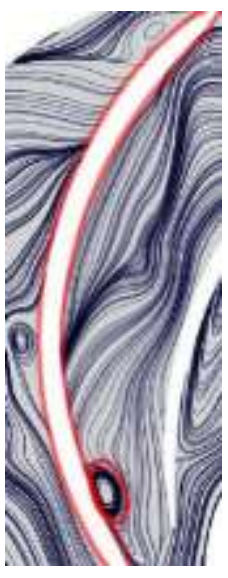

$(\mathrm{d}) \mathrm{t}=0.4366 \mathrm{~s}$

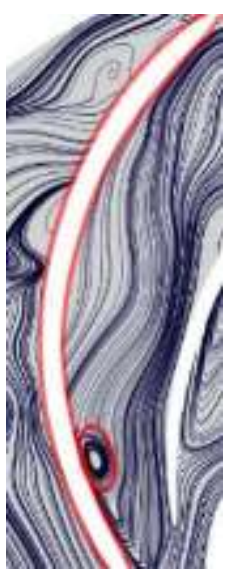

(e) $\mathrm{t}=0.4426 \mathrm{~s}$

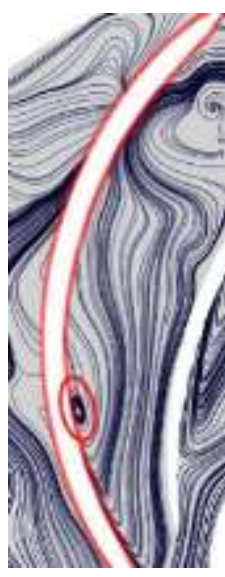

(f) $t=0.4538 \mathrm{~s}$

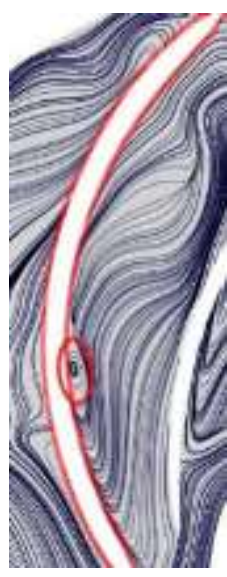

(g) $\mathrm{t}=0.4698 \mathrm{~s}$ 
Fig.6 Channel(No.1 blade channel) snapshot of the evolution of the vortex in one cycle
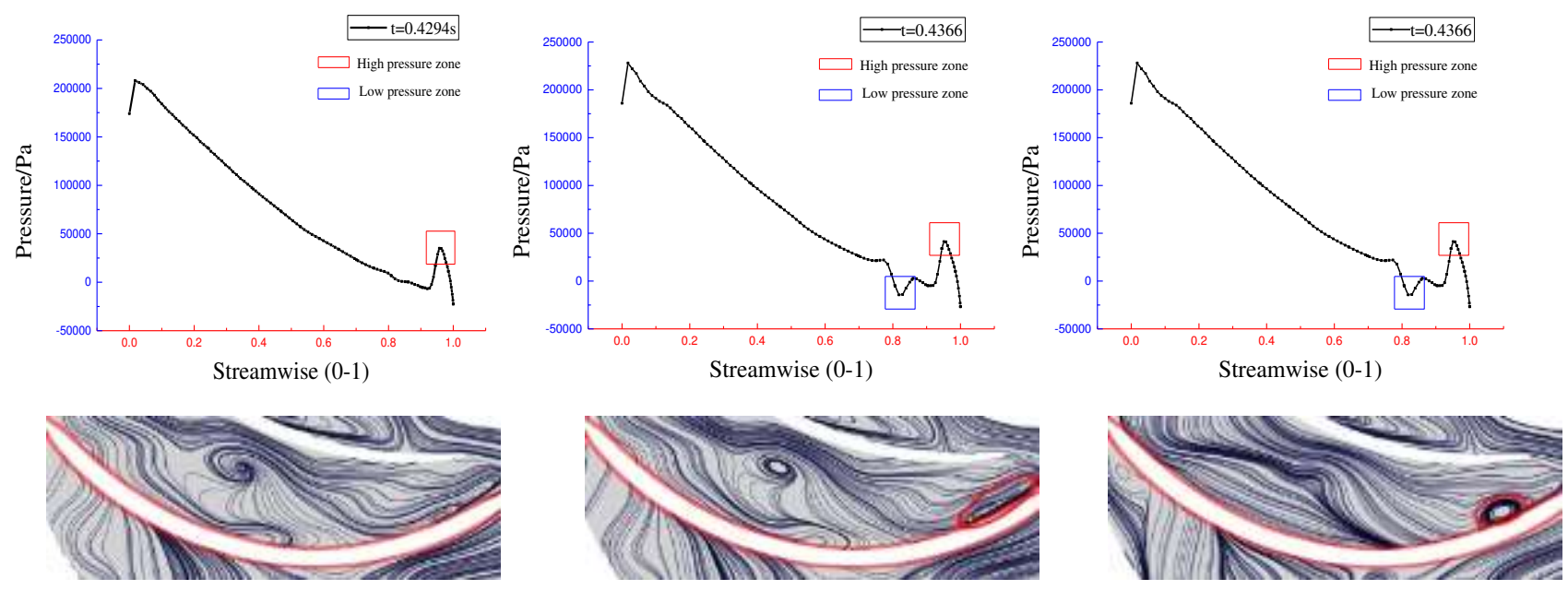

(a) $\mathrm{t}=0.4294 \mathrm{~s}$

(b) $\mathrm{t}=0.4310 \mathrm{~s}$

(c) $\mathrm{t}=0.4366 \mathrm{~s}$
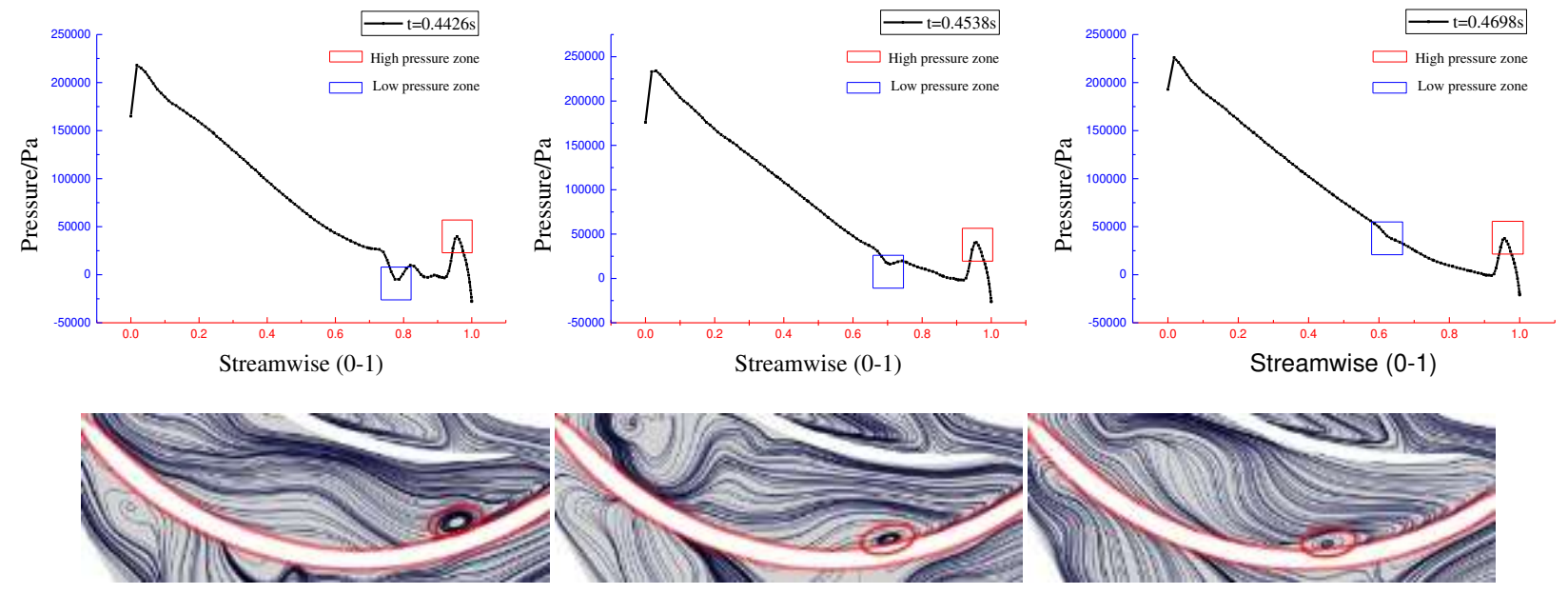

(d) $\mathrm{t}=0.4426 \mathrm{~s}$

(e) $\mathrm{t}=0.4538 \mathrm{~s}$

(f) $t=0.4698 \mathrm{~s}$

Fig.7 Blade pressure load distribution 

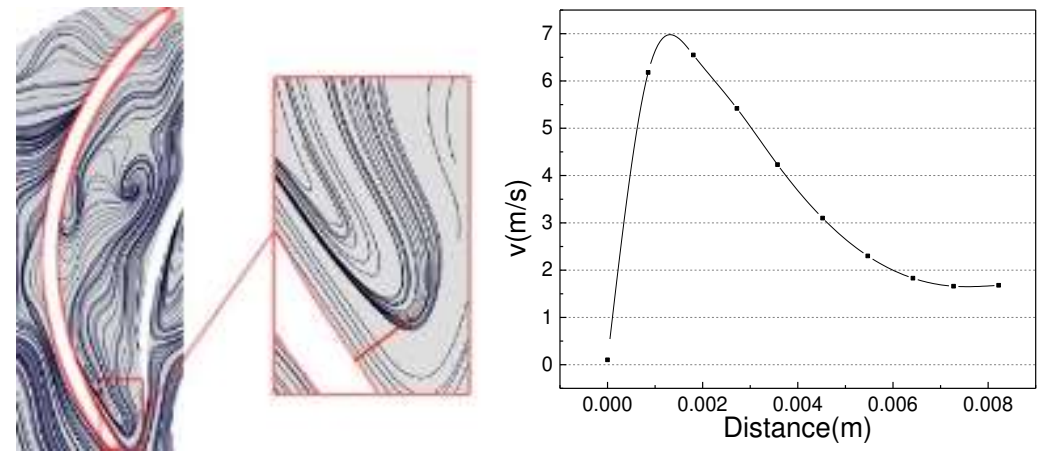

(b)

(b)

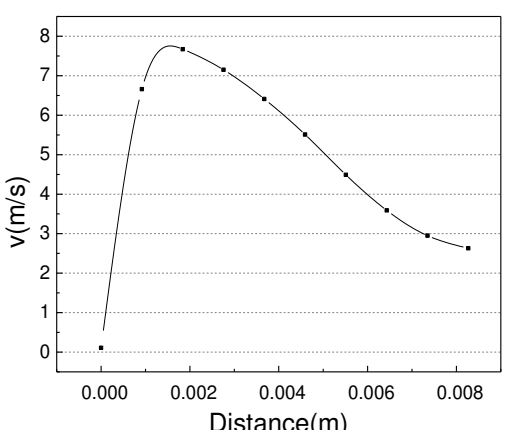

(c)

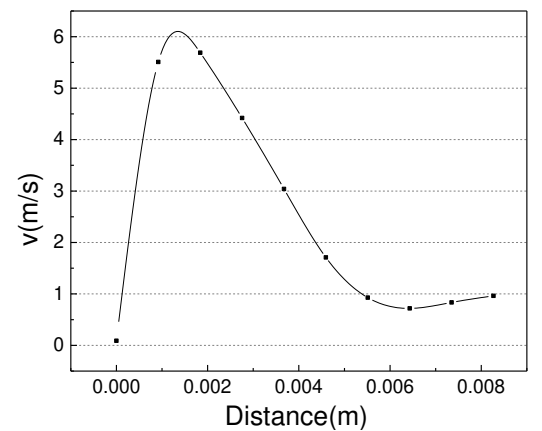

(d)

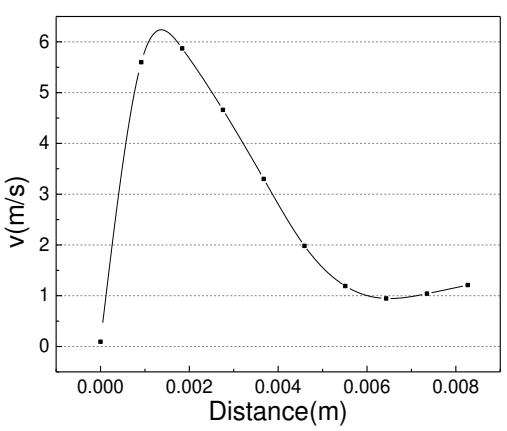

(e)

Fig.8 Tangential velocity distribution

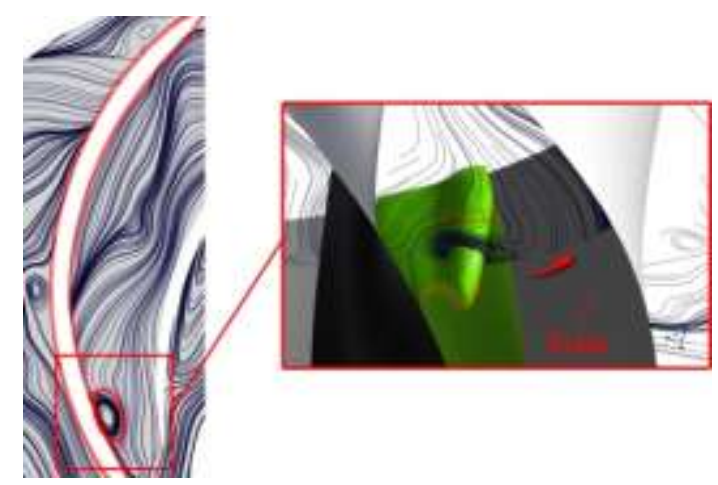

Fig.9Blade spanwise vorticity structure 


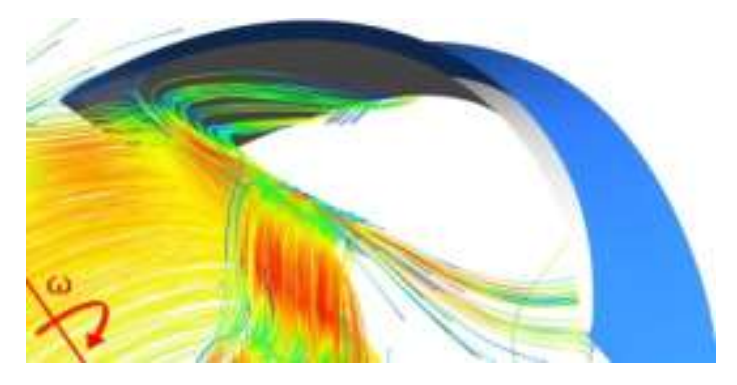

Fig.10 Streamline at the outlet of blade

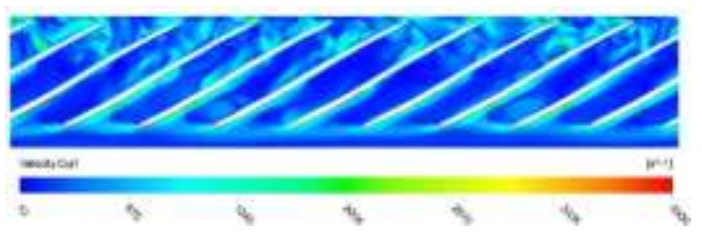

Fig.11Vorticity contour of blade channels

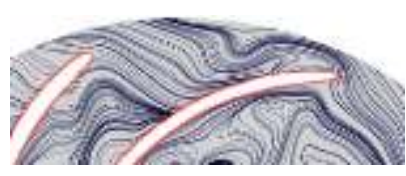

(a) $t=0.4296 \mathrm{~s}$

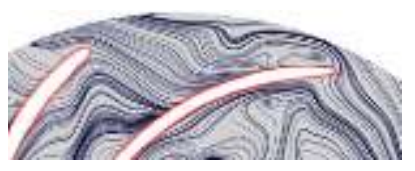

(b) $\mathrm{t}=0.4306 \mathrm{~s}$
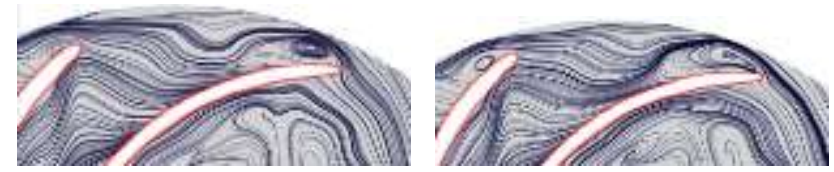

(c) $\mathrm{t}=0.4334 \mathrm{~s}$

(d) $\mathrm{t}=0.4352 \mathrm{~s}$

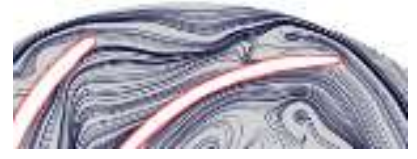

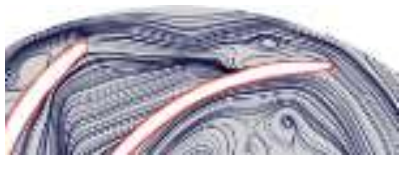

(f) $\mathrm{t}=0.4388 \mathrm{~s}$

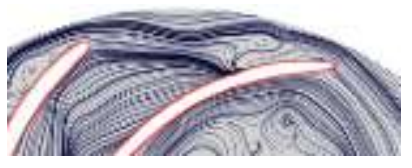

(g) $\mathrm{t}=0.4396 \mathrm{~s}$

Fig.12 Streamline of inlet of blade

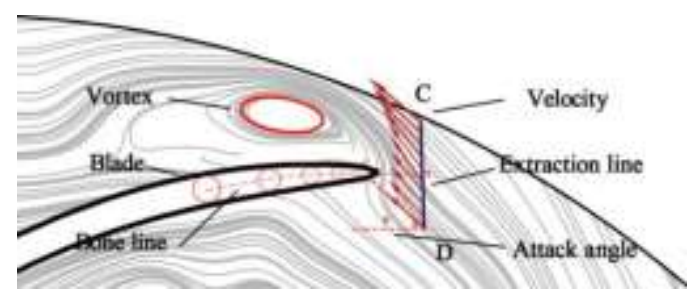

(a) 


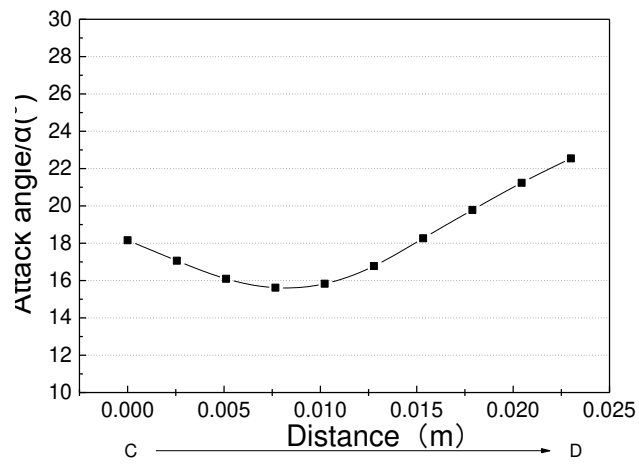

(b)

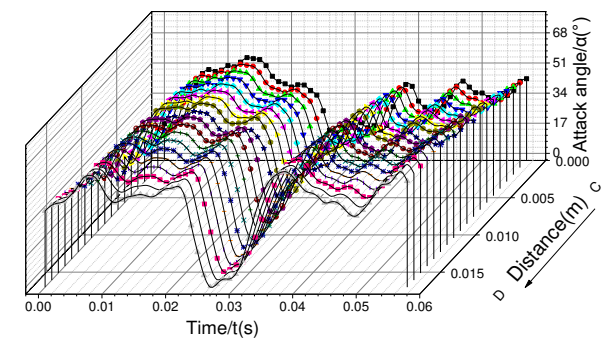

(c)

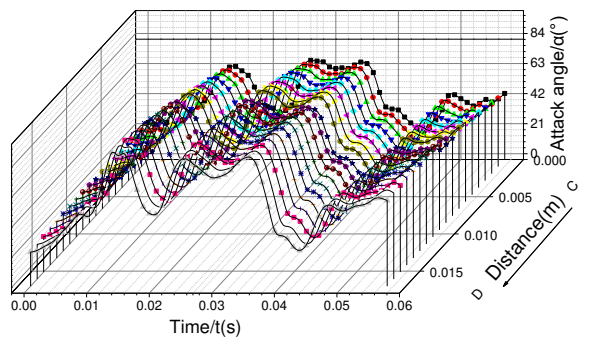

(d)

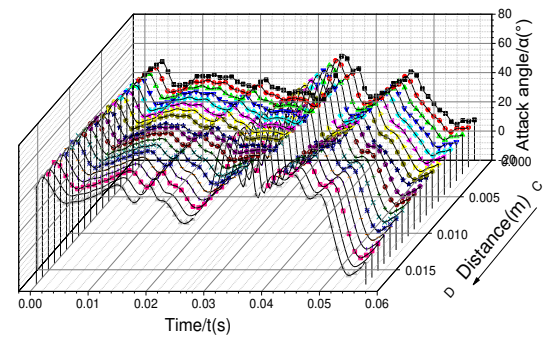

(e)

Fig.13Distribution of attack angle

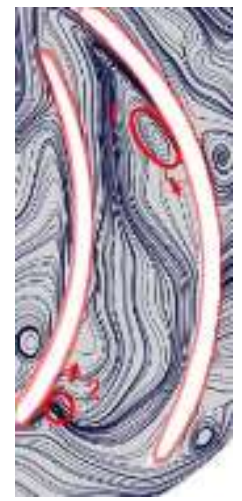

(a) $\mathrm{t}=0.4420 \mathrm{~s}$

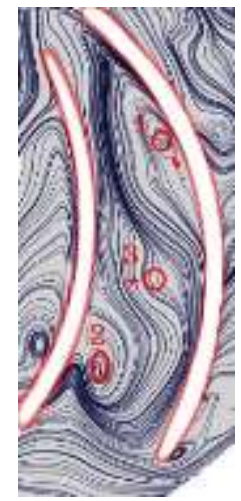

(b) $\mathrm{t}=0.4450 \mathrm{~s}$

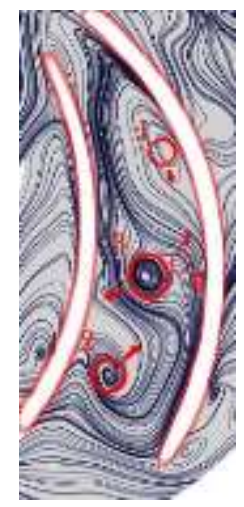

(c) $\mathrm{t}=0.4470 \mathrm{~s}$

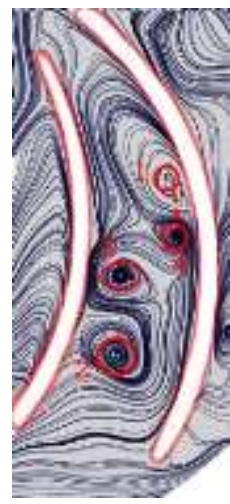

(d) $\mathrm{t}=0.4530 \mathrm{~s}$

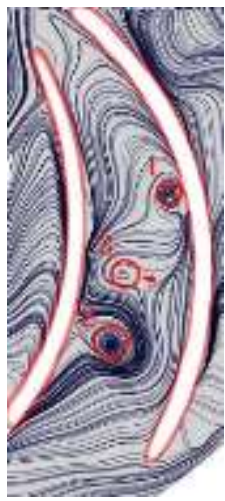

(e) $\mathrm{t}=0.4552 \mathrm{~s}$
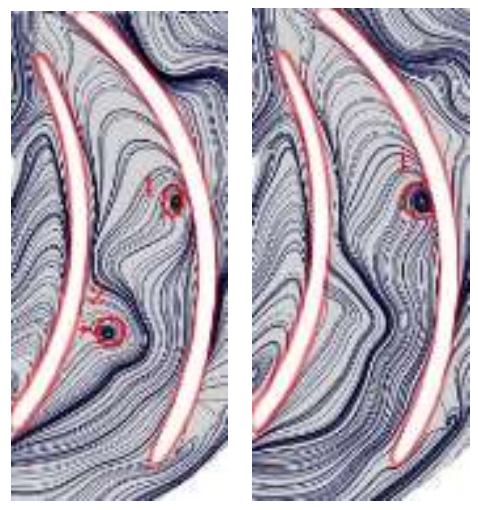

(f) $\mathrm{t}=0.4582 \mathrm{~s}$

(g) $\mathrm{t}=0.4618 \mathrm{~s}$

Fig.14Evolution of coherent structure in the middle of the blade channel 
Figures

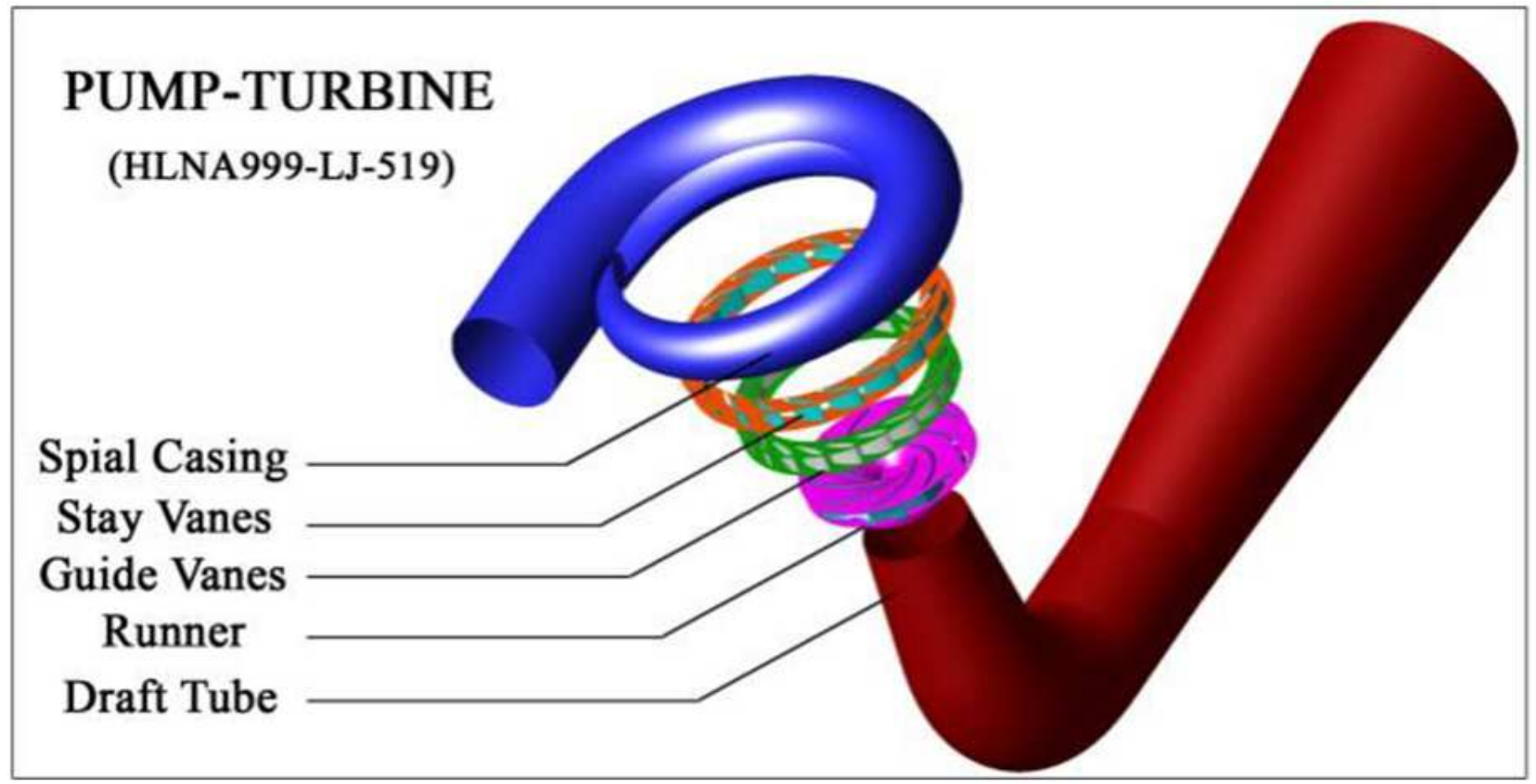

Figure 1

Computational domain of pump-turbine model

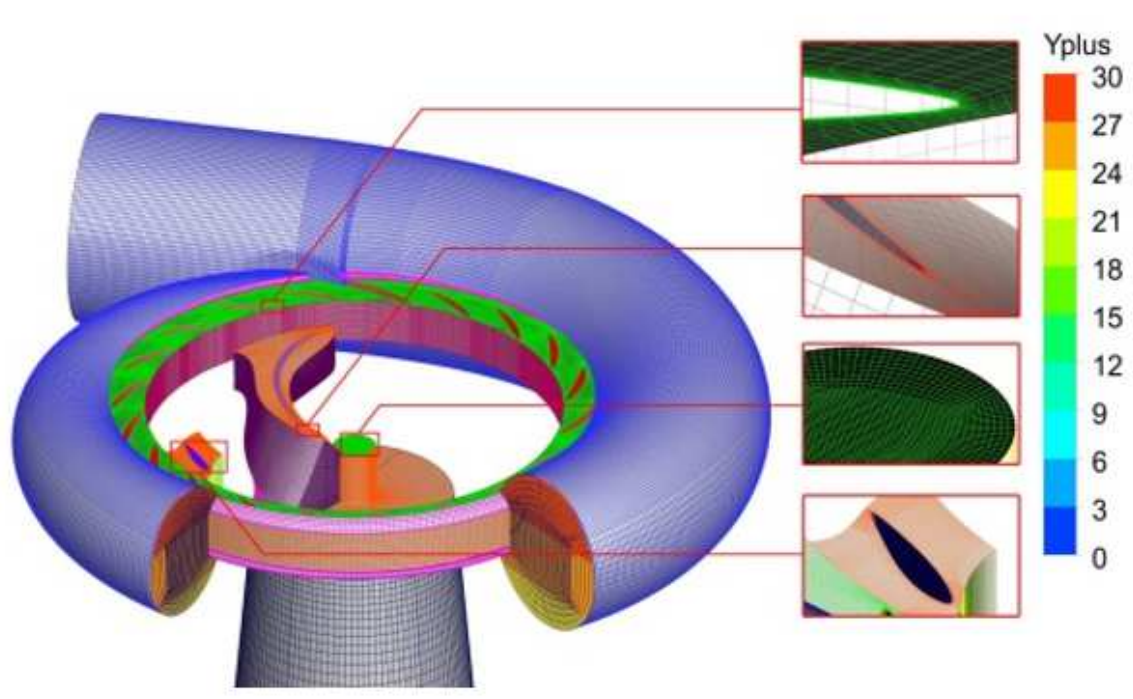

(a)

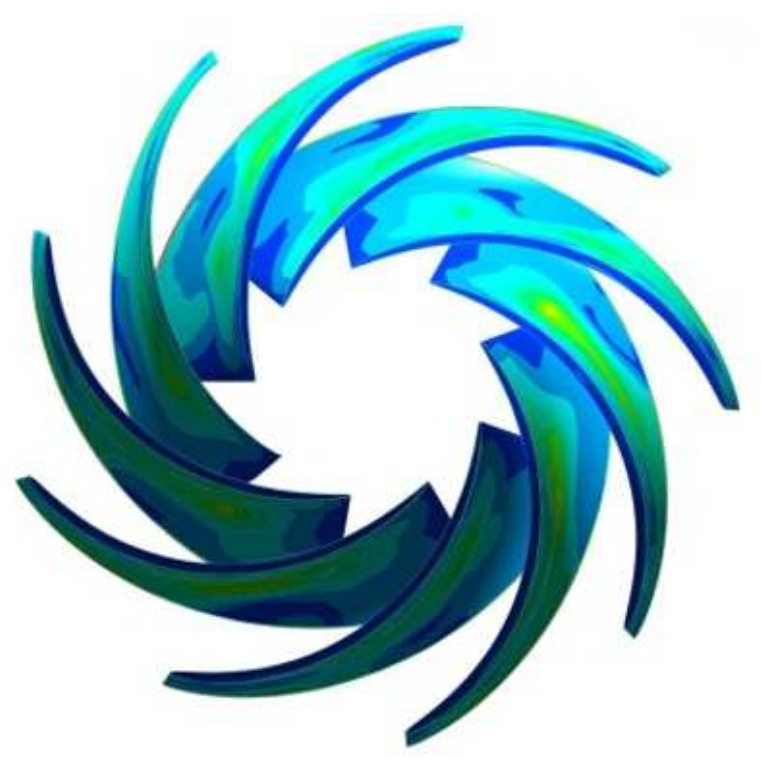

(b)

Figure 2

Mesh pattern of model pump-turbine. (a) Whole configuration mesh; (b) $Y+$ distribution of blade 


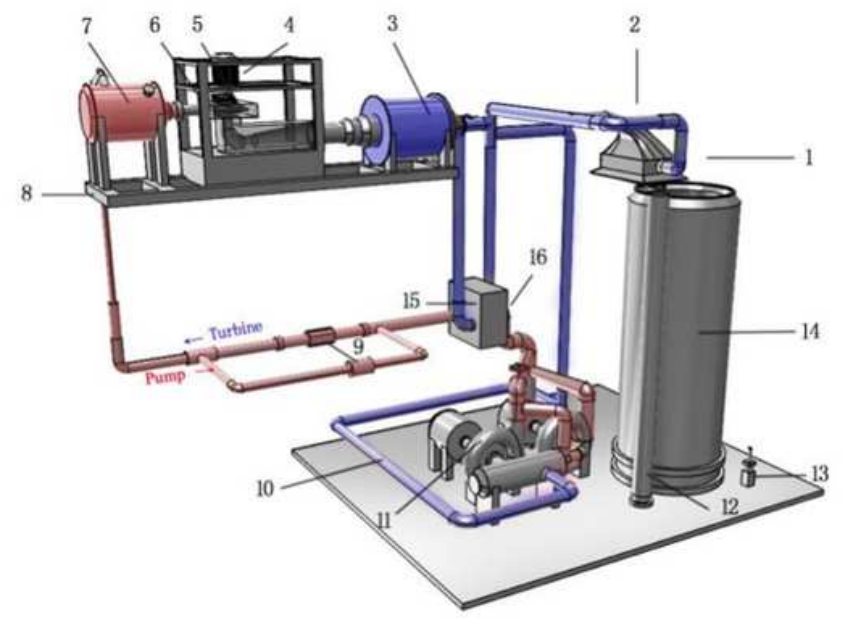

(a)
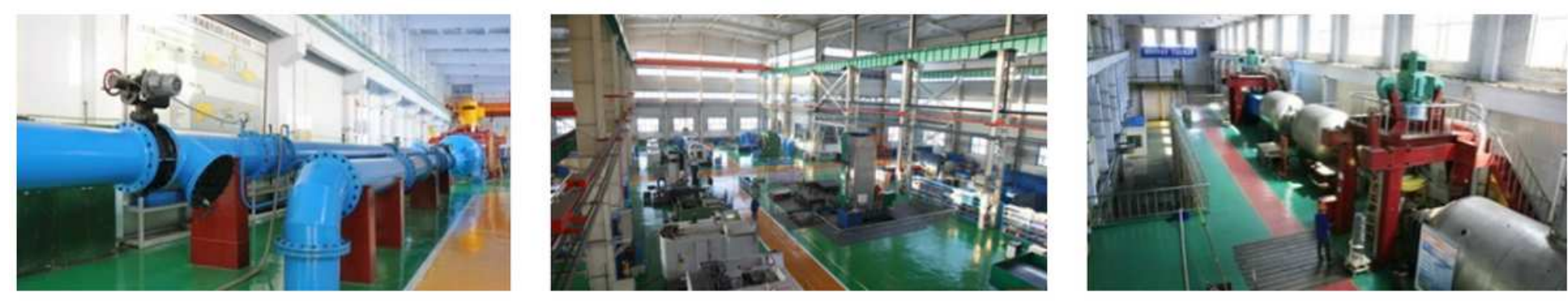

(b)

Figure 3

Sketch of the test bench (a) and the real test bench (b) used for performing tests under the runaway condition

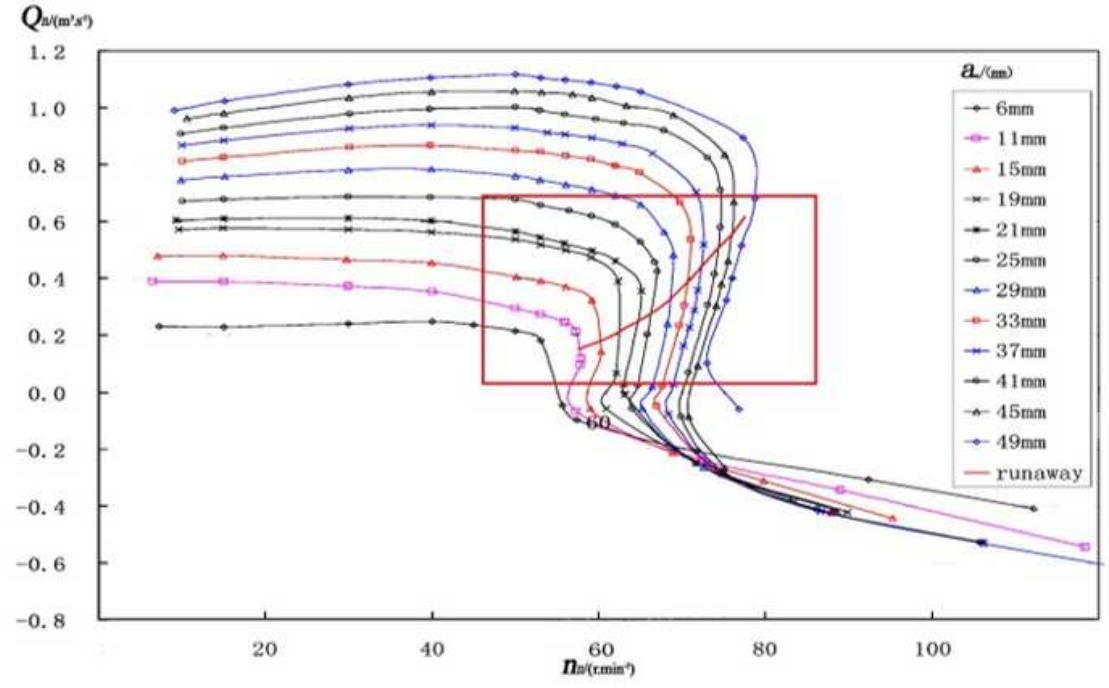

(a)

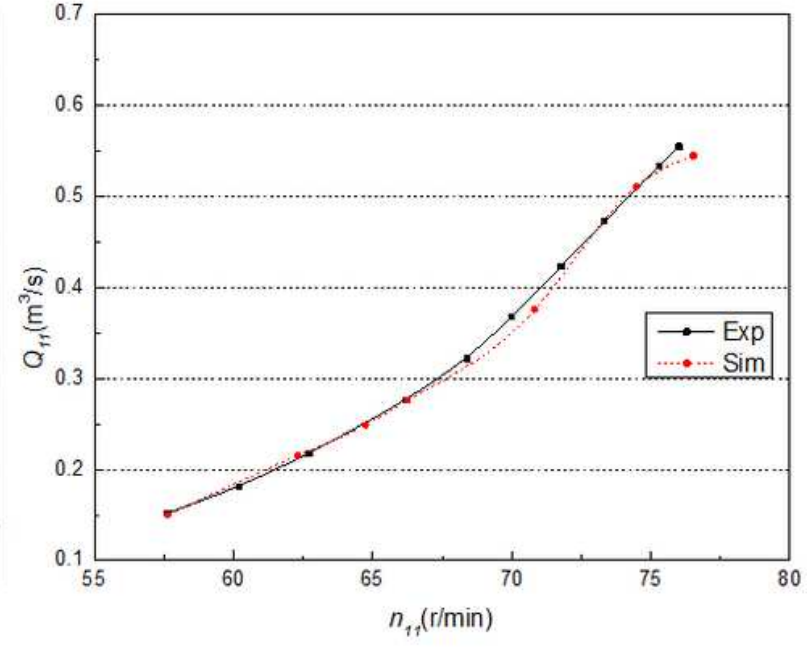

(b)

Figure 4 
Comparison of calculated and experimental results

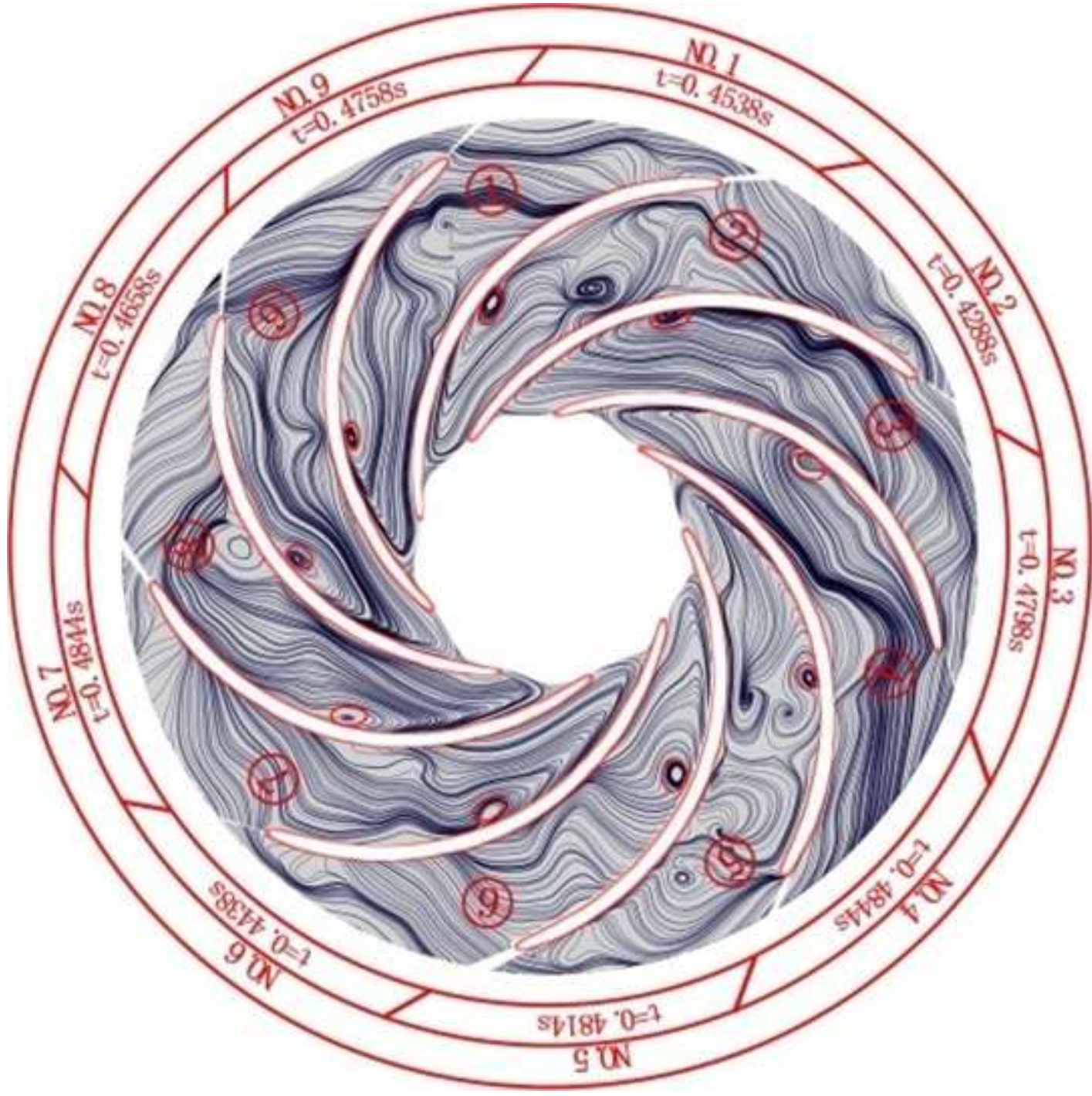

Figure 5

The number of blade channels and channel vortices at different times

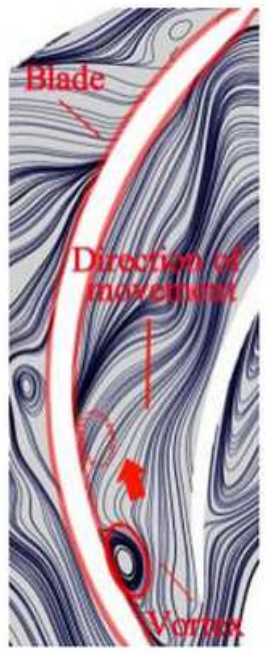

(a) $\mathrm{t}=0.4364 \mathrm{~s}$

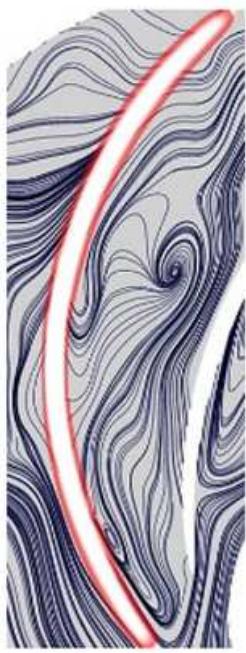

(b) $\mathrm{t}=0.4294 \mathrm{~s}$

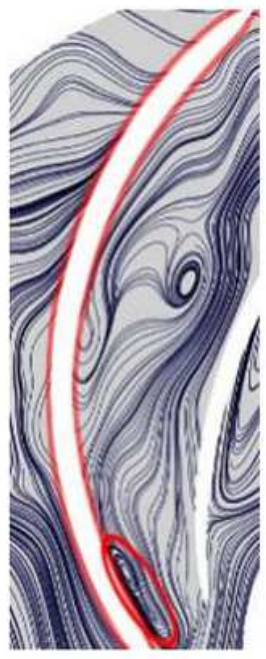

(c) $\mathrm{t}=0.4310 \mathrm{~s}$

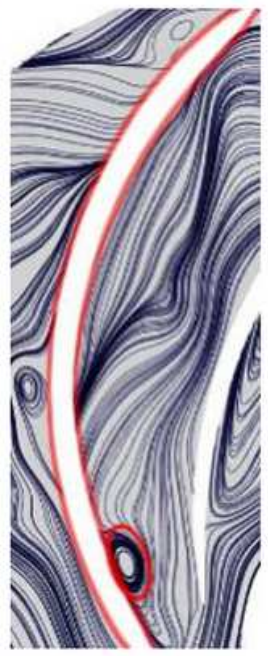

(d) $\mathrm{t}=0.4366 \mathrm{~s}$

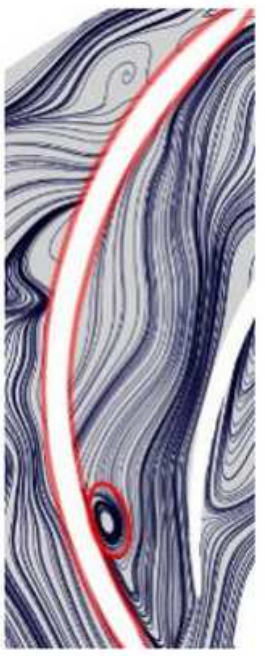

(e) $\mathrm{t}=0.4426 \mathrm{~s}$

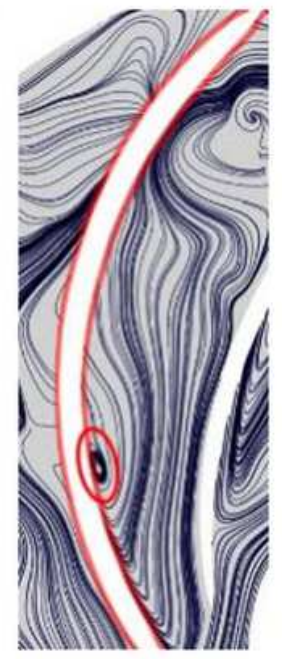

(f) $\mathrm{t}=0.4538 \mathrm{~s}$

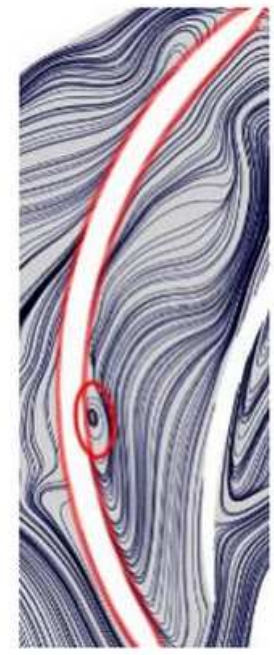

(g) $t=0.4698 \mathrm{~s}$ 
Figure 6

Channel(No.1 blade channel) snapshot of the evolution of the vortex in one cycle
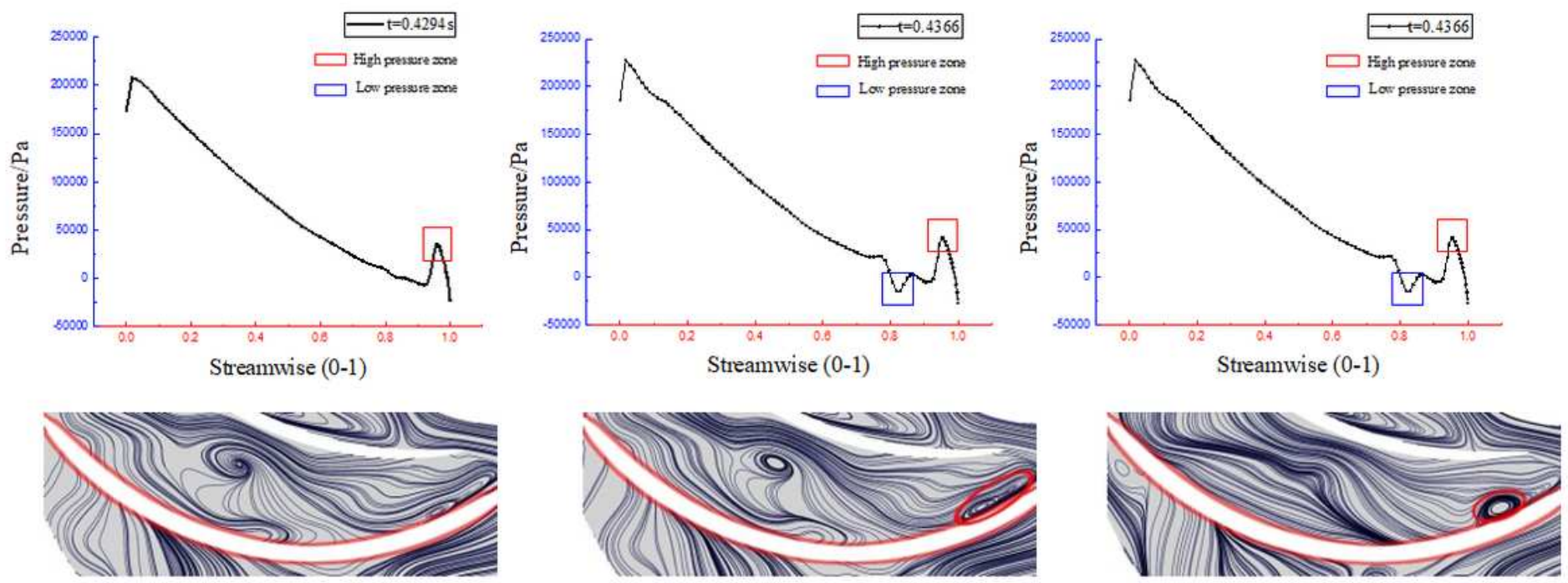

(a) $t=0.4294 \mathrm{~s}$

(b) $\mathrm{t}=0.4310 \mathrm{~s}$

(c) $\mathrm{t}=0.4366 \mathrm{~s}$
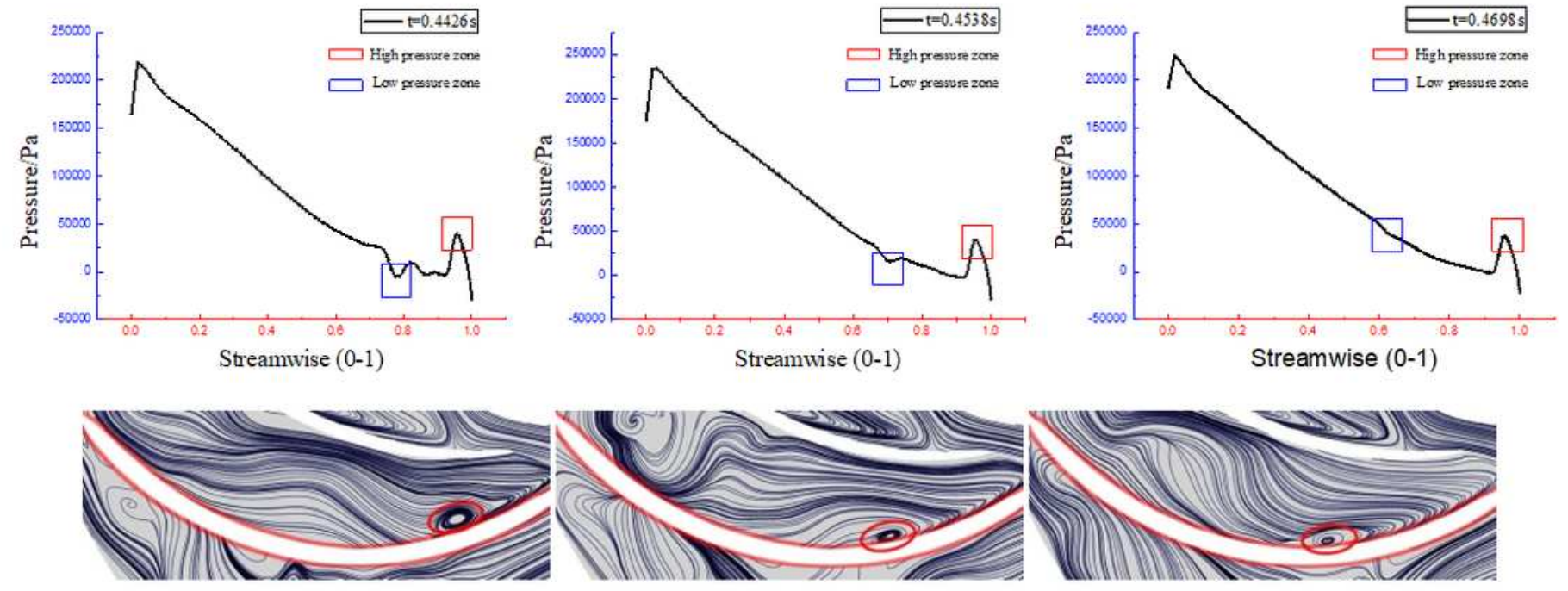

(d) $\mathrm{t}=0.4426 \mathrm{~s}$

(e) $\mathrm{t}=0.4538 \mathrm{~s}$

(f) $\mathrm{t}=0.4698 \mathrm{~s}$

Figure 7

Blade pressure load distribution 


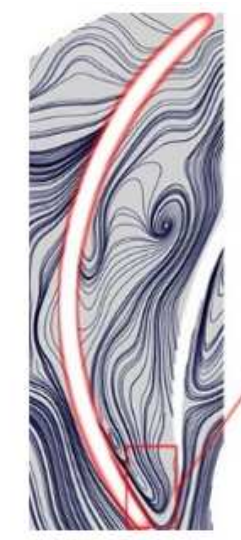

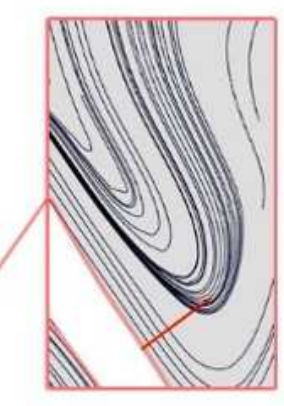

(a)

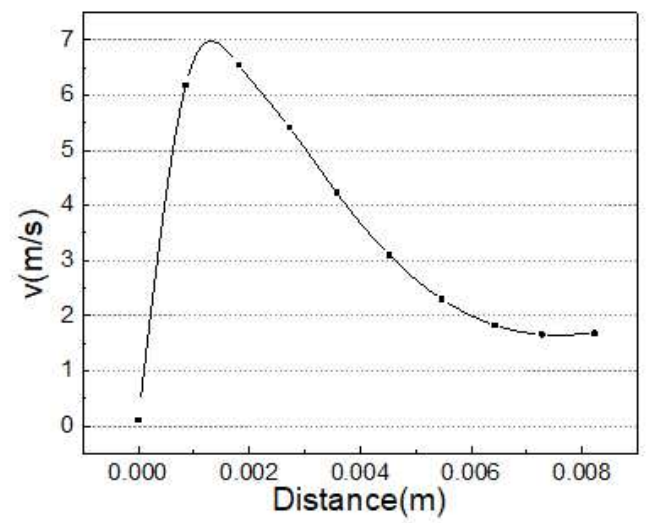

(b)

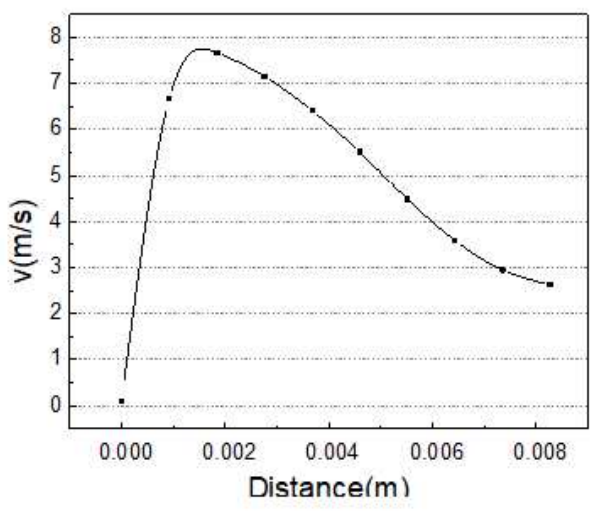

(c)

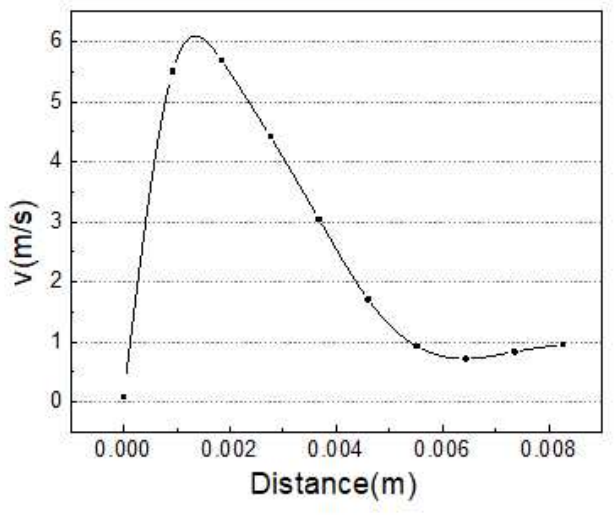

(d)

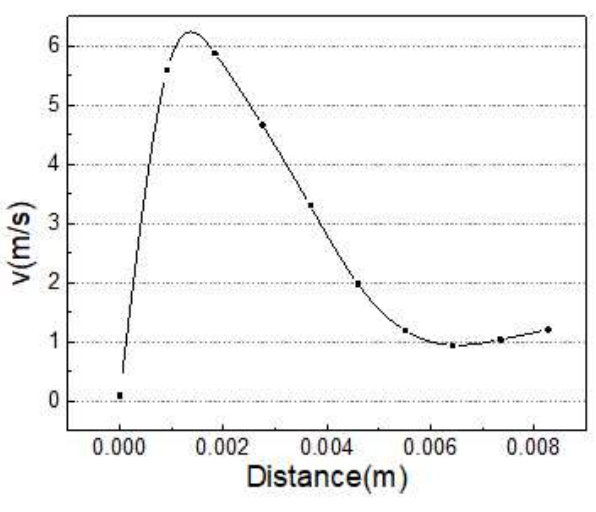

(e)

\section{Figure 8}

Tangential velocity distribution
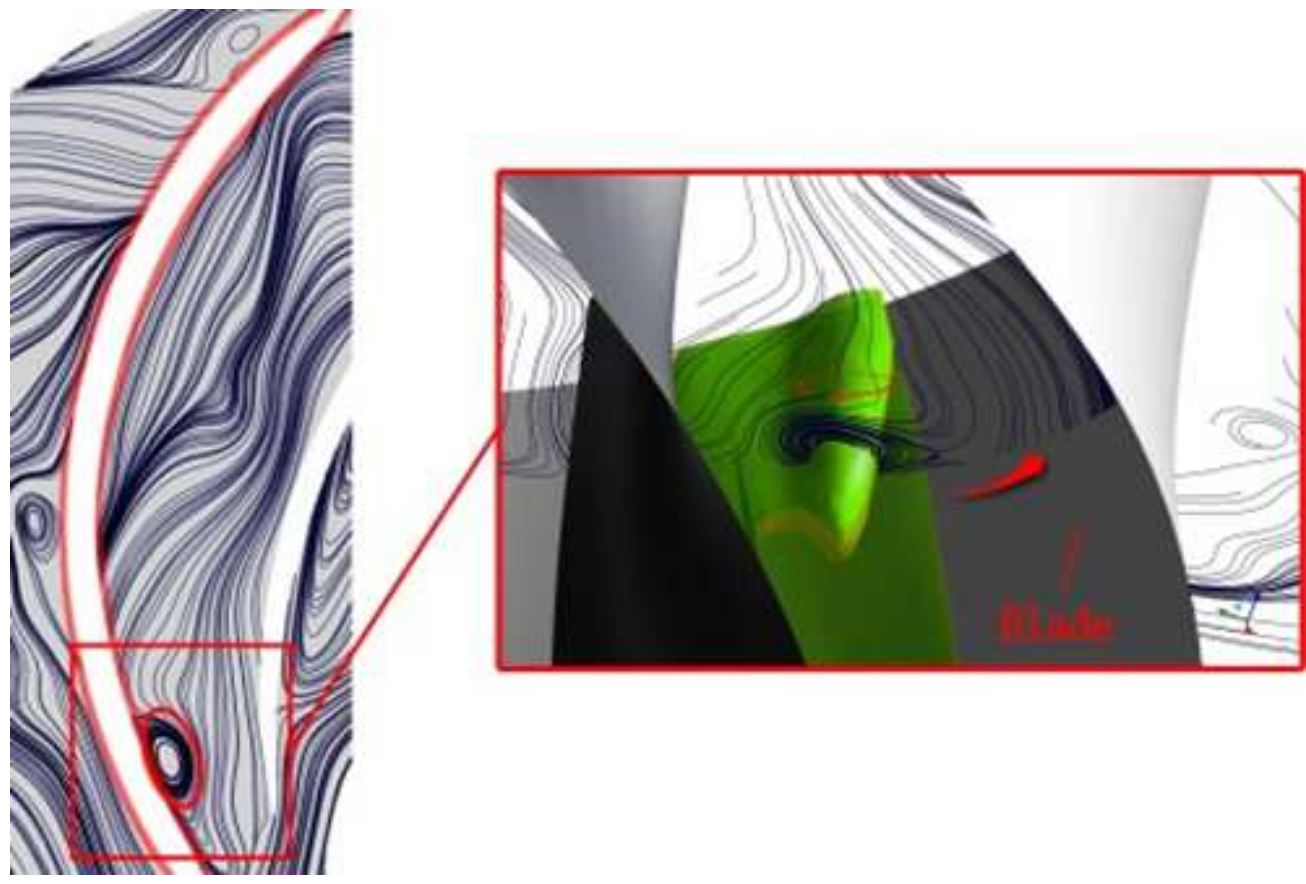

Figure 9 
Blade spanwise vorticity structure

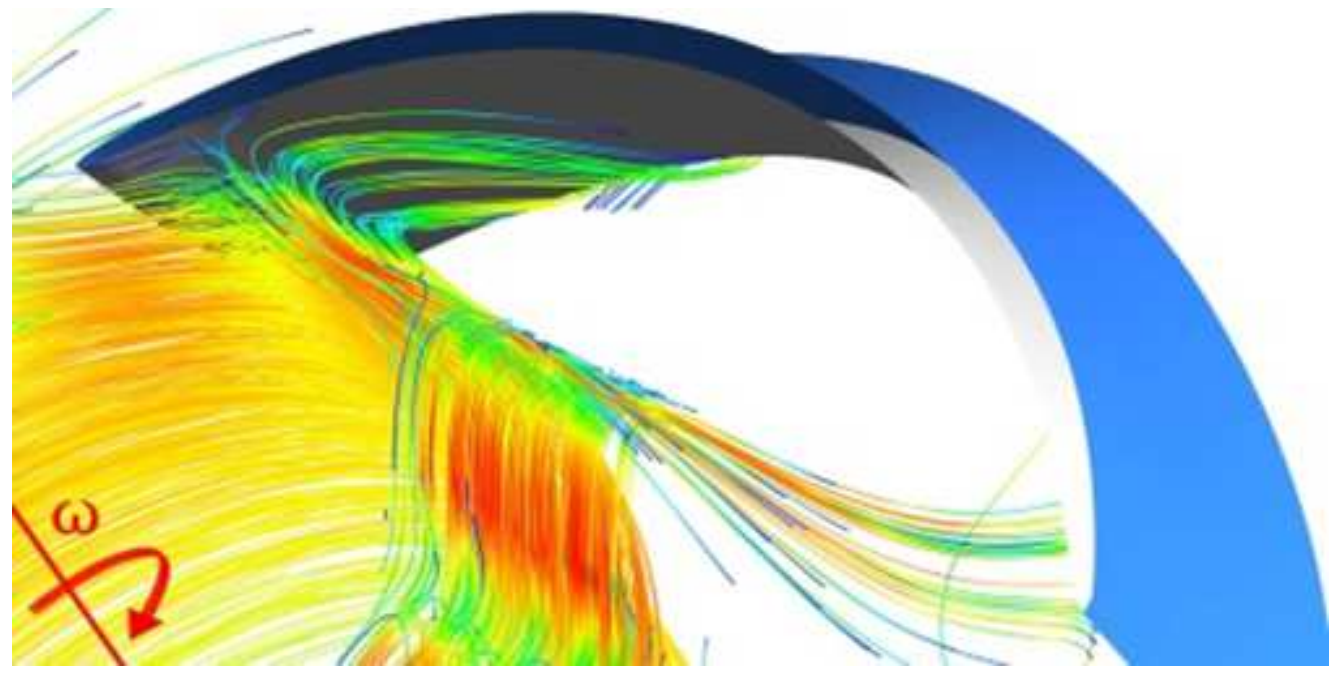

Figure 10

Streamline at the outlet of blade

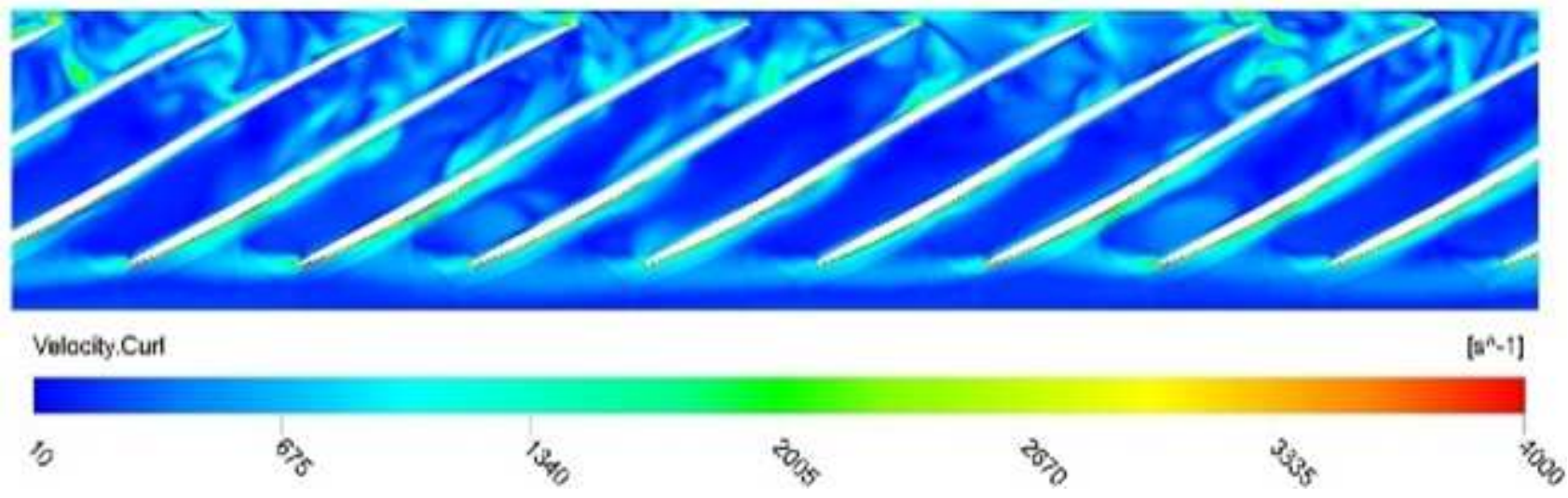

\section{Figure 11}

Vorticity contour of blade channels

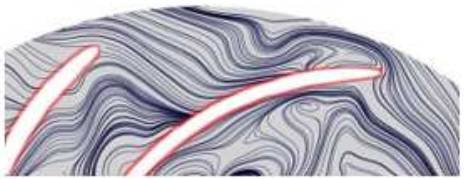

(a) $\mathrm{t}=0.4296 \mathrm{~s}$

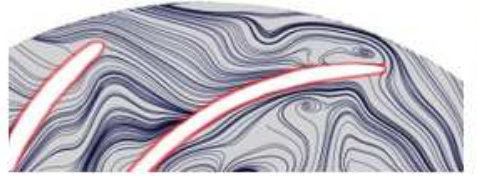

(b) $\mathrm{t}=0.4306 \mathrm{~s}$

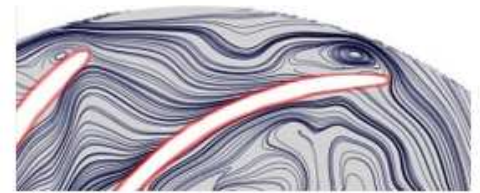

(c) $\mathrm{t}=0.4334 \mathrm{~s}$

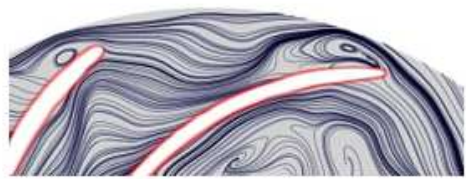

(d) $\mathrm{t}=0.4352 \mathrm{~s}$

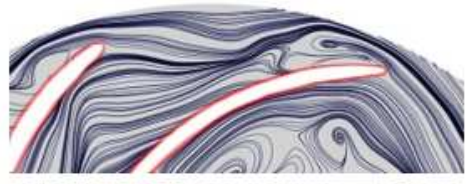

(e) $\mathrm{t}=0.4378 \mathrm{~s}$

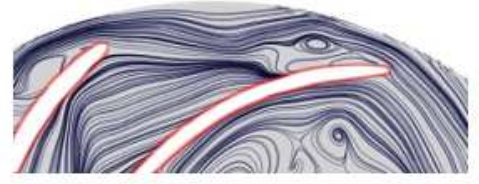

(f) $\mathrm{t}=0.4388 \mathrm{~s}$

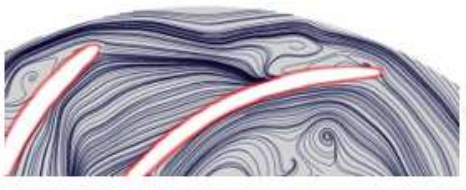

(g) $\mathrm{t}=0.4396 \mathrm{~s}$

Figure 12

Streamline of inlet of blade 


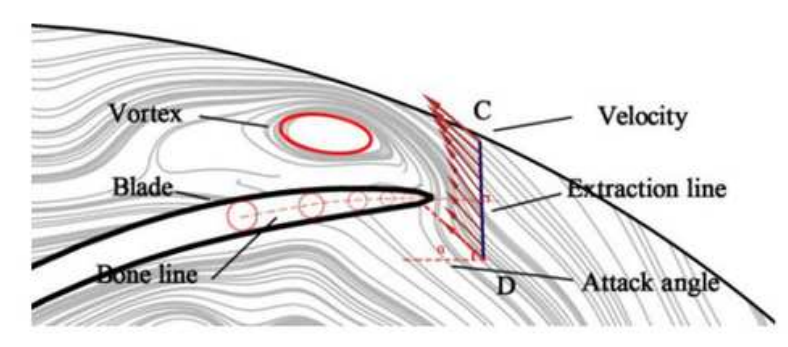

(a)

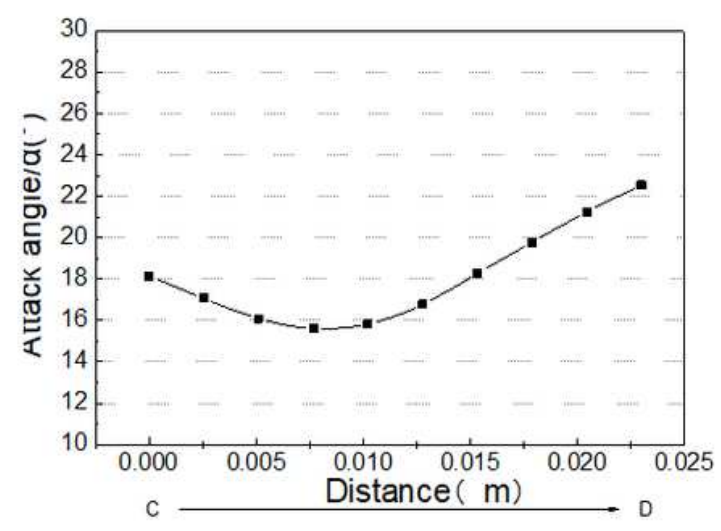

(b)

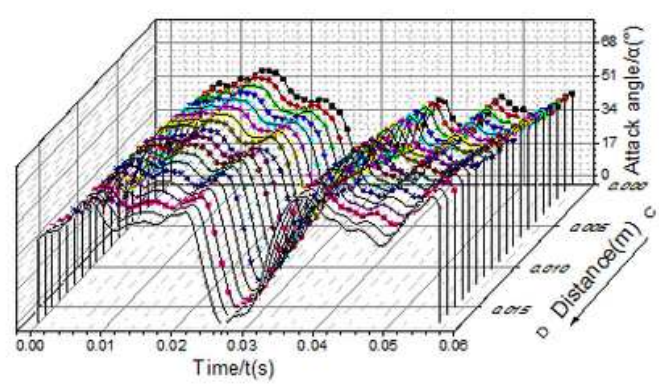

(c)

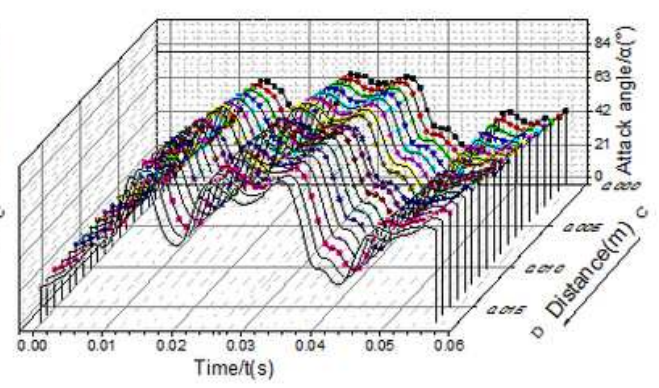

(d)

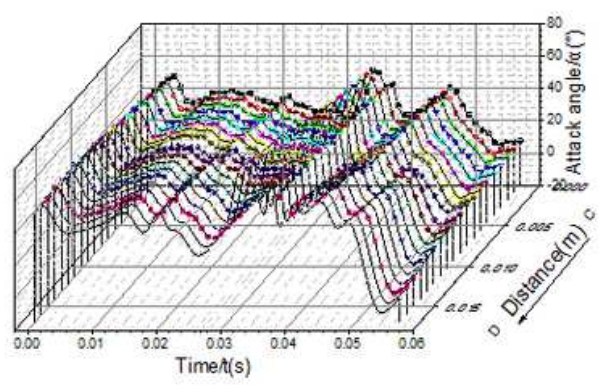

(e)

Figure 13

Distribution of attack angle

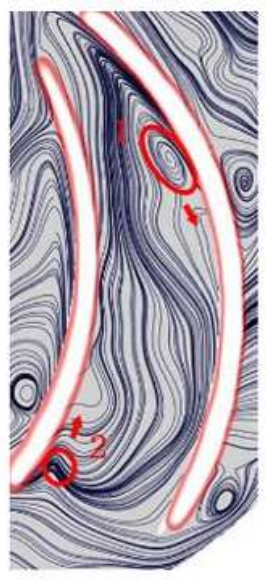

(a) $\mathrm{t}=0.4420 \mathrm{~s}$

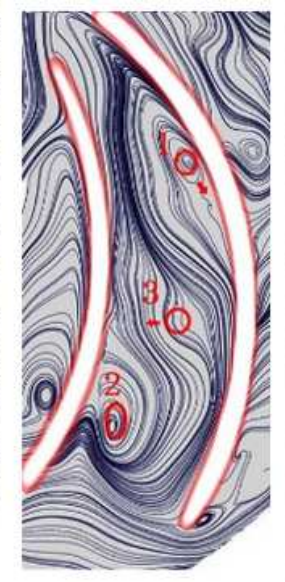

(b) $\mathrm{t}=0.4450 \mathrm{~s}$

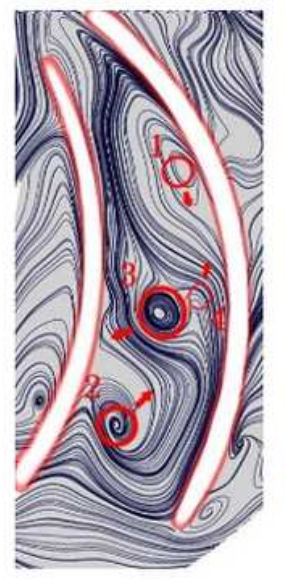

(c) $\mathrm{t}=0.4470 \mathrm{~s}$

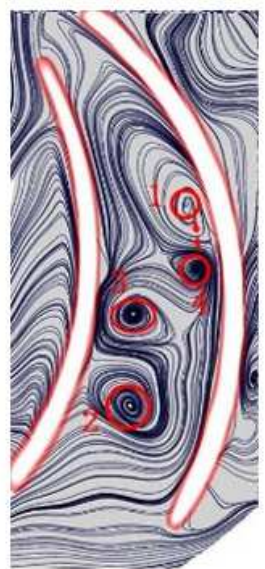

(d) $\mathrm{t}=0.4530 \mathrm{~s}$

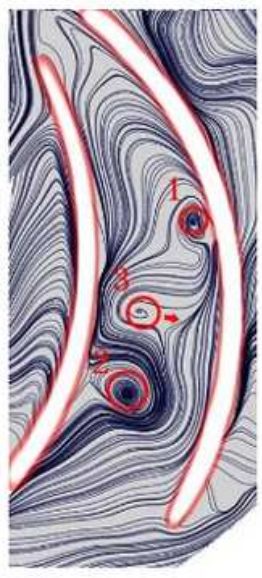

(e) $\mathrm{t}=0.4552 \mathrm{~s}$

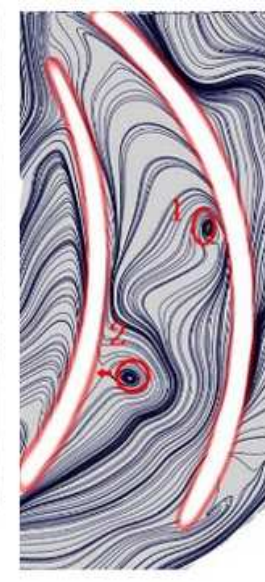

(f) $\mathrm{t}=0.4582 \mathrm{~s}$

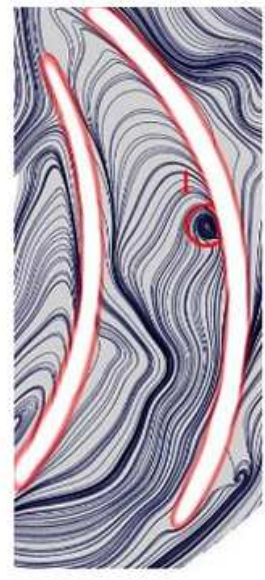

(g) $\mathrm{t}=0.4618 \mathrm{~s}$

\section{Figure 14}

Evolution of coherent structure in the middle of the blade channel 